\title{
$\Delta 9$-tetrahydrocannabinol (THC)-rich compositions from canna- bis have cytotoxic activity against ovarian cancer cells and act synergistically with niraparib in vitro
}

\author{
Nurit Shalev ${ }^{1}$, Michelle Kendall ${ }^{2}$, Seegehalli M Anil ${ }^{1}$, Ajjampura C Vinayaka ${ }^{1}$, Hinanit Koltai ${ }^{*}$ \\ ${ }^{1}$ Institute of Plant Science, Agriculture Research Organization, Volcani Center, Rishon LeZion, Israel. nu- \\ ritsh@volcani.agri.gov.il ; aniganapath@gmail.com; ac.vinayaka@gmail.com; hkoltai@volcani.agri.gov.il \\ 2 Canna Onc Research, Santa Barbara, California, USA. CannaOncResearch@gmail.com \\ * Correspondence: hkoltai@agri.gov.il; Tel.: +972-3-9683039 (H.K.)
}

\begin{abstract}
Simple Summary: Ovarian cancer (OC) is the second most common and the most lethal gynecologic malignancy in the western world. Cannabis is used for many medical treatments, yet only a few studies examine the effectivity of cannabis compounds against $\mathrm{OC}$ or the combination of various cannabis molecules. Here we have identified fractions from a high $\Delta 9$-tetrahydrocannabinol (THC) cannabis strain and cannabis compounds that substantially reduce OC cell viability and cell motility. Moreover, synergistic activity is identified between the cannabis fractions and niraparib, an antineoplastic targeted-therapy drug used to treat OC. Our results indicate that cannabis might be regarded as a complementary and effective anti-cancer treatment for OC. Given the favorable safety profile of cannabis compounds compared to the standard care of pharmacotherapy agents, clinical trials with cannabis-based products are desperately needed for the OC patient population.
\end{abstract}

\begin{abstract}
Ovarian cancer (OC) is the most lethal gynecologic malignancy. Cannabis sativa is being used to treat different medical conditions. We sought to examine the effectiveness of combinations of cannabis compounds against OC. Cytotoxic activity was determined by XTT assay on HTB75 and HTB161 cell lines. Apoptosis and cell cycle were determined by fluorescence-activated cell sorting (FACS). Gene expression was determined by quantitative PCR. The two most active fractions, F5 and F7, from a high $\Delta 9$-tetrahydrocannabinol (THC) cannabis strain extract and their standard mix (SM) showed cytotoxic activity against OC cells. The most effective phytocannabinoid combination was THC+cannabichromene (CBC)+cannabigerol (CBG). F5, F7 and SM affected cell cycle, led to cell apoptosis and to a marked reduction in cell migration. Moreover, these fractions act in synergy with niraparib, and were $\sim 50$ fold more cytotoxic to OC cells than to normal keratenocytes. Niraparib+F7 treatment was effective on OC patient's cells. F7 and the niraparin+fraction (F5 and F7) treatments reduced Mitogen-Activated Protein Kinase 4 (MAPK4) gene expression; this reduction may act in synergy with the niraparib inhibition of Poly (ADP-ribose) polymerase 1 (PARP1) activity. Combinations of cannabis compounds and niraparib should be examined for efficacy in pre-clinical studies and clinical trials.
\end{abstract}

Keywords: ovarian cancer, cannabis, phytocannabinoids, apoptosis, cytotoxicity, cell cycle, MAPK4, PARP1 
A Graphical Abstract

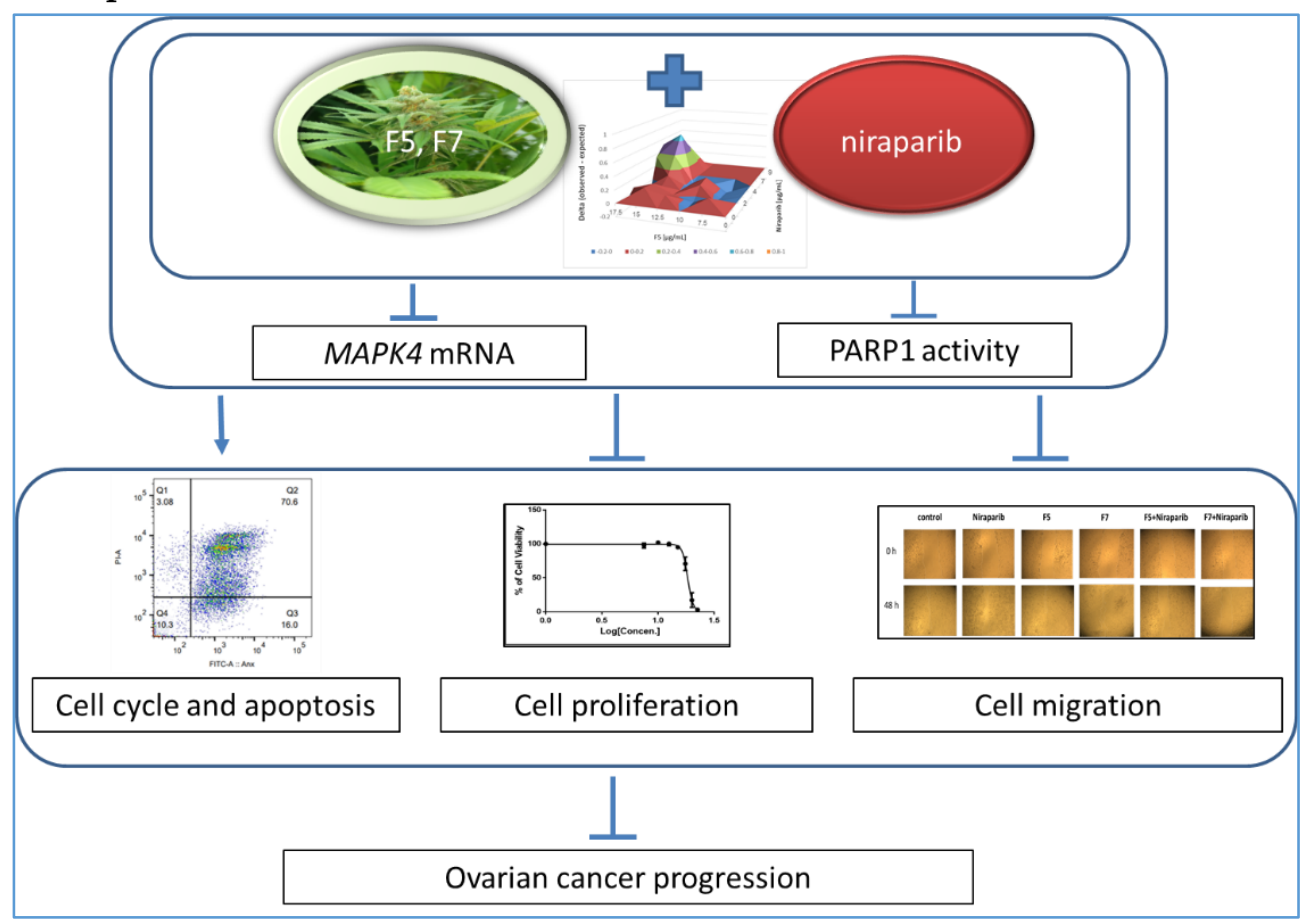

\section{Introduction}

Ovarian cancer $(\mathrm{OC})$ is the second most common and the most lethal gynecologic malignancy in the western world; about $70 \%$ of cases are diagnosed at an advanced stage. Late-stage ovarian cancer is incurable in the majority of cases [1]. In the United States, it is estimated there will be 21,410 new diagnoses of OC and 13,770 OC deaths [2]. Epithelial OC typically presents in postmenopausal women, with a few months of abdominal pain and distension, vague and subtle symptoms that are often dismissed. Many women go 6 months before being properly diagnosed. Also, there is no screening test for OC and population level monitoring does not reduce mortality [3]. Most women have advanced disease, for which the standard of care remains surgery and platinum-based cytotoxic chemotherapy [4]. In about $80 \%$ of the cases disease relapse is expected, on average after 24 months, and ultimately multi-drug resistance develops, with very few women surviving five years after diagnosis.

Cannabis sativa is being used worldwide to alleviate numerous symptoms associated with medical conditions [5]. C. sativa strains produce several dozen compounds in each strain. In total, the species produces around 600 different molecules, including more than 150 phytocannabinoids and hundreds of terpenes [6-8]. Recently, a large number of studies demonstrated that many phytocannabinoids have anticancer activity in vitro and in vivo, and lead to e.g., inhibition of cell proliferation and migration, inhibition of angiogenesis, and induction of apoptosis in prostate, skin, lung, glioma and breast cancer cells [9-11].

However, only a few studies have examined the effectivity of cannabis compounds against OC. Cannabidiol (CBD) was shown to have anti-proliferative activity in a OC cell line and in a chick embryo model (i.e., in ovo) and administration of CBD in solution or carried by nanoparticles in combination with paclitaxel increased paclitaxel effectivity in vitro and in ovo $[12,13]$. In a single patient case study, the use of Laetrile and 'CBD oil' improved expression of markers associated with low-grade serous ovarian cancer [14]. However, 'CBD oil' may contain multiple compounds extracted from cannabis in addition to $\mathrm{CBD}$ and the actual combination(s) of cannabis molecules that might be effective against OC was not identified.

Here, we identified fractions of cannabis extract and combinations of cannabis compounds that have cytotoxic activity against OC cells. These combinations of cannabis com- 
pounds affected cell cycle and led to cell apoptosis. Moreover, these fractions act in synergy with niraparib in vitro; the synergetic mixture of niraparib+F5 or niraparib+F7 was $\sim 50$ fold more cytotoxic to OC cells than to normal keratinocytes.

\section{Materials and Methods}

\subsection{Plant extraction}

The dry inflorescence of the high $\Delta 9$-tetrahydrocannabinol (THC) C. sativa strain Dairy Queen (DQ) (IMC, Israel) was extracted as described previously [15]. Decarboxylation was carried out by heating the dry extract to $220{ }^{\circ} \mathrm{C}$ for $10 \mathrm{~min}$. The heated extract was dissolved in methanol and filtered through a $0.45 \mu \mathrm{m}$ syringe filter. Following evaporation, the weighted vials were re-suspended in methanol to the desired concentration.

\subsection{Extract fractionation}

A flash chromatography apparatus (Flash Pure, Buchi, C-810) equipped with a diode array detector was used to fractionate the decarboxylated crude extract. An Ecoflex C-18 $80 \mathrm{~g}, 50 \mu \mathrm{m}$ spherical, max. pressure 180 psi column was used for separation, with $80-85 \%$ methanol in water as the mobile phase. The flow rate was $30 \mathrm{~mL} / \mathrm{min}$. The organic solvent (methanol) of each fraction was separately removed by using a rotary vacuum evaporator at $30^{\circ} \mathrm{C}$. The remaining aqueous phase containing the compound of interest was lyophilized to obtain a dried powder. Each dried fraction tube was weighed separately and reconstituted by methanol to produce the required concentrations, and stored at $-20^{\circ} \mathrm{C}$.

\subsection{Chemical analysis}

High performance liquid chromatography (HPLC, 1260 Infinity II, Agilent) equipped with a Raptor ARC-18 for LC-UV column ( $150 \mathrm{~mm} \times 4.6 \mathrm{~mm}$ ID, pore size $2.7 \mu \mathrm{m})$ was used for chemical analysis as previously described [16]. A gas chromatography-mass spectrometer (GC8860-MS5977B Agilent) equipped with $30 \mathrm{~m}, 0.25 \mathrm{~mm}$ ID, 5\% crosslinked phenylmethyl siloxane capillary column (HP-5MS) with $0.25-\mu \mathrm{m}$ film thickness, was used for chemical analysis as described in [16]. $10 \mu \mathrm{L}$ of each sample fraction was transferred into GC vials with an insert, dried under a gentle stream of nitrogen and dissolved in $100 \mu \mathrm{L}$ of hexane. Sample volume for injection was $1 \mu \mathrm{L}$. Helium was used as the carrier gas at a constant flow of $1.1 \mathrm{~mL} \mathrm{~s}^{-1}$. An isothermal hold at $50^{\circ} \mathrm{C}$ was maintained for $2 \mathrm{~min}$, followed by a heating gradient of $6^{\circ} \mathrm{C} \mathrm{min}^{-1}$ to $300^{\circ} \mathrm{C}$, and the final temperature was held for $4 \mathrm{~min}$. Peaks were assigned using spectral libraries (NIST 14.0 and 17.0) and compared with MS data obtained from the injection of standards purchased from LGC Standards.

\subsection{Standard/material preparation and use}

The cannabinoid standards at a concentration of $1 \mathrm{mg} / \mathrm{mL}$ in methanol used in this study included THC (Restek catalog no. 34067), cannabichromene (CBC, Restek catalog no. 34092), cannabigerol (CBG, Restek catalog no. 34091), tetrahydrocannabivarin (THCV, Restek catalog no. 34100) cannabinol (CBN, Restek catalog no. 34010) and cannabidivarin (CBDV, Restek catalog no. 34123). Inverse agonists (IA) to CB1 and CB2 were AM251 (ab120088; Abcam) and SR144528 (ab146185; Abcam), respectively. The TRPA1 blocker used was HC-030031 (ab120554; Abcam). TRPV1 and TRPV2 antagonists were ab141772 (Abcam) and Tranilast 1098/10 (Abcam), respectively. All IAs were dissolved in dimethyl sulfoxide (DMSO) at a concentration of $10 \mathrm{mM}$ and used for cell treatment at a final concentration of $10 \mu \mathrm{M}$. Chemotherapy solutions for synergy tests included niraparib (AG0038ZU, Angene, China) and gemcitabine (461060010 Acros Organics, China). Analytical grade methanol and Dimethyl sulfoxide (DMSO) were used according to the indicated concentration of the treatment. Ultra-pure deionized water (MS grade) was used as received without further purification. 


\subsection{Cell Culture}

CAOV-3 (ATCC, HTB75; Adenocarcinoma) and OVCAR-3 (ATCC, HTB161; Adenocarcinoma) cell lines were cultured in Dulbecco's Modified Eagle Medium (DMEM) medium (01-055-1A, Biological Industries, Israel) supplemented with 10\% fetal bovine serum (FBS) (04-127-1A, Biological Industries, Israel), and in RPMI medium (01-100-1A, Biological Industries, Israel), supplemented with $20 \%$ FBS, respectively. Both media were supplemented with $1 \%$ Pen-Strep, $1 \%$ L-Glutamine and $0.02 \%$ plasmocin. Cells were incubated in $37{ }^{\circ} \mathrm{C}$ in a humidified atmosphere containing $5 \% \mathrm{CO}_{2}-95 \%$ air.

\subsection{Isolation of OC cells from patient $M K$}

One cancerous deep femoral lymph node was removed from OC patient MK by a gynecological oncology surgeon. The node was placed in sterile saline solution, and a cold pack was activated for immediate overnight shipping to SEngine Precision Medicine (Seattle, WA, USA). The node was processed and grown into an organoid $[17,18]$. Genetic testing on MK's cells showed no germline or 2 somatic mutation, but showed mutant TP53 C135Y and STK11 splice site 735-1G>C. Immunohistochemistry of tumor indicates strongly positive for PAX8, WT1, negative for BRCA.

\subsection{Cell Viability Assay}

Cells were seeded into 96-well plates at density of $1 \times 10^{4}$ per well (in $50 \mu \mathrm{L} /$ well) in complete medium and were incubated at $37^{\circ} \mathrm{C}$ incubator overnight to allow attachment. The following day, cells were treated in triplicate with plant extracts, fractions, or cannabinoids standards in volume of $50 \mu \mathrm{L} /$ well at different concentrations, as mentioned in each experiment. Solvents (methanol and/or DMSO) were used as a negative control and niraparib was used as a positive control in all the biological assays. In experiments where CB1 or CB2 inverse agonists, TRPV1 or TRPV2 antagonists, or TRPA1 blocker were used, they were added along with the treatment at concentration of $10 \mu \mathrm{M} / \mathrm{mL}$. Treated cells were incubated for $48 \mathrm{~h}$ at $37^{\circ} \mathrm{C}$. Subsequently, XTT reagents (2,3,-bis (2-methoxy- 4-nitro5-sulfophenyl)- 5-[(phenylamino)- carbonyl]-2H- tetrazolium inner salt) (20-300-1000, Biological Industries, Israel) were added to the cells for $2 \mathrm{~h}$ at $37^{\circ} \mathrm{C}$ in a humidified $5 \% \mathrm{CO}_{2}-$ 95\% air atmosphere. Absorbance was recorded using a Synergy H1 hybrid reader photometer (BioTek) at $490 \mathrm{~nm}$ with a $650 \mathrm{~nm}$ reference wavelength. Cell viability was estimated using the equation: \%Cell Viability $=100 \times((A 490-A 650)$ of treatment $\div$ (A490 - A650) of solvent control). A490 and A650 are the absorbencies of the XTT colorimetric reaction. Absorbance of the media alone (blank) was substracted from the readings. For dose response assay, GraphPad Prism version 6.1 (https://www.graphpad.com/scientific-software/prism/, GraphPad Software Inc., San Diego, USA) was employed to produce dose-response curves (data points were connected by non-linear regression lines of the sigmoidal dose-response relation) and determination of IC50 values. For assay of full confluence, cells were seeded in 96-well plates at density of $1 \times 10^{4}$ per well (in $100 \mu \mathrm{L} /$ well) in complete medium and were incubated at $37^{\circ} \mathrm{C}$ for 5 days to allow $100 \%$ confluence.

\subsection{Apoptosis Assay}

Apoptosis for HTB-75 cell line was assessed using the MEBCYTO Apoptosis Kit with Annexin V-FITC and PI (MBL, Enco, 4700). Staining was carried out according to manufacturer instructions. In brief, cells were seeded in a 6-well TC plates at a density of $5 \times 10^{5}$ cells in $2 \mathrm{~mL}$ medium per well, $24 \mathrm{~h}$ before treatment. The treatment period was $48 \mathrm{~h}$, and cells were harvested after applying $250 \mu \mathrm{L}$ trypsin for $5 \mathrm{~min}$, adding a complete medium to neutralize the trypsin, and centrifuging for $5 \mathrm{~min}$ at $1600 \mathrm{rpm}$. Cell pellets were resuspended and washed twice with $1 \mathrm{~mL}$ of phosphate buffered saline (PBS). The cells in each sample were resuspended in $85 \mu \mathrm{L}$ of Annexin binding buffer. Cells were stained with 10 $\mu \mathrm{L}$ of Annexin V- FITC solution and $5 \mu \mathrm{L}$ of propidium iodide (PI) working solution followed by incubation in the dark at room temperature for $15 \mathrm{~min}$. Next, $400 \mu \mathrm{L}$ of Annexin 
$\mathrm{V}$ binding buffer was added to each tube and flow cytometry was performed using a Gallios flow cytometer (FACS). Cells were considered apoptotic if they were Annexin V+/PI(early apoptosis) or Annexin V+/PI+ (late apoptosis). Live cells were defined as Annexin $\mathrm{V}-/ \mathrm{PI}-$, and Annexin V-/PI+ as necrotic.

\subsection{Cell cycle analysis}

HTB-75 (CAOV-3) cells were seeded in 6-well TC plates at a concentration of $5 \times 10^{5}$ cells in $2 \mathrm{~mL}$ medium per well, $24 \mathrm{~h}$ before treatment. The treatment period was $48 \mathrm{~h}$, and cells were harvested after applying $250 \mu \mathrm{L}$ trypsin for $5 \mathrm{~min}$, adding a complete medium to neutralize the trypsin, and centrifuging for $5 \mathrm{~min}$ at $1600 \mathrm{rpm}$. The cell pellet was washed once with $1 \mathrm{~mL}$ of PBS and fixed with $70 \%$ cold ethanol overnight at $-20^{\circ} \mathrm{C}$. The fixed cells were washed twice with $1 \mathrm{~mL}$ of PBS and stained with $250 \mu \mathrm{L}$ of PI solution (40 $\mu \mathrm{g} / \mathrm{mL}$ ) containing RNase A (100 $\mu \mathrm{g} / \mathrm{mL})$ for $30 \mathrm{~min}$ in dark. $250 \mu \mathrm{L}$ of PBS was added to each tube and the cells were analyzed using FACS.

\subsection{Scratch-wound Assay}

HTB75 cells were seeded into a 96-well plate at a density of $2 \times 10^{4}$ per well in $100 \mu \mathrm{L}$ of complete medium. After $24 \mathrm{~h}$, cells in each well were scratched perpendicularly across the center of the well with a $200 \mu \mathrm{L}$ pipette tip to produce a cell-free area for investigating the ability of the cells to migrate and close the gap under different treatments. Immediately after scratching, $100 \mu \mathrm{L}$ of treatment solution was added. Photos were taken at 0,24 , 30 , and $48 \mathrm{~h}$ following scratching, and the gap area was measured using ImageJ (version $1.53 a)$. The scratch area, indicated by cells migrated into the scratch was calculated as percent of scratch area at time $x$ from time 0 :

$$
\frac{(x \mathrm{~h} \text { cell free area }) \times 100}{(0 \mathrm{~h} \text { cell free area })}
$$

\subsection{Analysis of combined drug effects}

Drug synergy was determined by the Bliss independence drug interaction model as described in [16], on HTB75 cells. Briefly, drug synergy was determined from XTT results using the Bliss independence drug interaction model, defined by the following equation: $E x y=E x+E y-(E x E y)$, where (Exy) is the additive effect of the drugs $\mathrm{x}$ and $\mathrm{y}$ as predicted by their individual effects (Ex and Ey).

\subsection{Quantitative real-time PCR}

Cells were seeded in a 6-well plate at a concentration of $1.5 \times 10^{6}$ cells in $3 \mathrm{~mL}$ medium per well. After $24 \mathrm{~h}$ incubation, cells were treated with cannabis compounds and/or chemotherapy drugs for $6 \mathrm{~h}$. Cells were harvested and RNA was extracted using TRI reagent (Merck). RNA was reverse-transcribed in a total volume of $20 \mu \mathrm{L}$ (PB30.11-10, qPCRBIO) according to manufacturer's protocol. PCR was performed in triplicate using a qPCR SyGreen Blue Mix (PB20.16-20, qPCRBIO) and StepOnePlus system (Applied Biosystems). The expression of each target gene was normalized to the expression of HPRT mRNA in the 2- $\Delta \Delta \mathrm{Ct}$ method presenting the differences $(\Delta)$ in threshold cycle $(\mathrm{Ct})$ between the target gene and HPRT gene. $\Delta \Delta \mathrm{Ct}=\Delta \mathrm{Ct}$ treatment- $\Delta \mathrm{Ct}$ control. Experiments were repeated three times. The primers included MAPK4 (Gene ID: 5596) (forward) 5'TGTCAATGGTTTGGTGCTGT- $3{ }^{\prime}$ and (reverse) 5' - TTTGACGATGTTGTCGTGGT -3'

\subsection{Statistical Analysis}

Results are presented in graphs as mean + standard error (SE) of replicate analyses and are either representative of, or include at least two independent experiments. Means of replicates were subjected to the Tukey-Kramer test using the JMP statistical package (https://www.jmp.com/en_us/home.html, SAS Inc, NC, USA) and considered significant when $\mathrm{P} \leq 0.05$. 


\section{Results}

\subsection{Determining cannabis strain with cytotoxic activity against ovarian cell lines}

Extracts of several $C$. sativa strains were examined for cytotoxic activity against ovarian cancer cell line HTB75. DQ (IMC, Israel), a high $\triangle 9$-tetrahydrocannabinol (THC) strain, was the most effective with the highest examined concentration $(20 \mu \mathrm{g} / \mathrm{mL})$ resulting in $\sim 50 \%$ cell death (Figure 1a). Other strains examined included GB-11 (THC:CBD:CBG 22:40:30, Israel GenenBank [IGB]), GB-14 (THC:CBD:CBG 55:9:28, IGB) and GB-18 (High THC, IGB) and a THC:CBD (22:35) strain (Paris, IMC). All these other strains showed no cytotoxic activity against the $\mathrm{OC}$ cells, even at $20 \mu \mathrm{g} / \mathrm{mL}$ (Figure 1a). IC50 for the DQ crude extract was determined to be $21.51 \mu \mathrm{g} / \mathrm{mL}$ (Figure 1b).
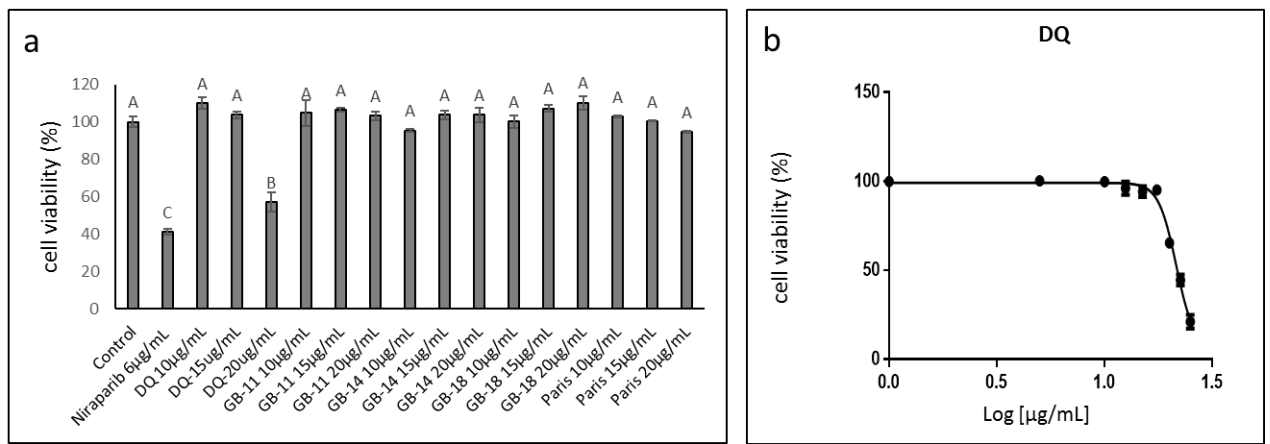

Figure 1. Cell viability of HTB75 cells (a) following treatment with crude extract of cannabis strains DQ, GB-11, GB-14, GB-18 and Paris. Cell viability was determined by XTT assay as a function of live cell number. Control is the vehicle-treated control $(1 \% \mathrm{v} / \mathrm{v}$ methanol). Error bars indicate $\pm S E(n=3)$. Levels with different letters are significantly different from all combinations of pairs according to the Tukey-Kramer honest significant difference (HSD; P $\leq 0.05$ ). (b) Cell viability following treatment with $C$. sativa DQ crude extract at different concentrations for IC50 value calculation from 5P logistic curve fit using GraphPad Prism version 6.1. Error bars indicate \pm SE $(n=3)$.

\subsection{Identification of active fractions of $D Q$ cannabis strain}

The most active extract, DQ, was fractionated as described in [15]. The activity of the fractions was tested on HTB75 cells. Four of the 11 fractions (F4, F5, F6 and F7) showed significant cytotoxic activity at the examined concentrations. F5 and F7 were the most active, at the highest examined concentration $(20 \mu \mathrm{g} / \mathrm{mL}$ ) resulting in $\sim 80 \%$ cell death (Figure 2a). F6 and F4 were less active, at the highest examined concentration $(20 \mu \mathrm{g} / \mathrm{mL})$ resulting in $\sim 60 \%$ and $\sim 40 \%$ cell death, respectively (Figure $2 \mathrm{a}$ ). Treatments with F1-F3 and F8 showed no cytotoxic activity against HTB75 cells (Figure 2a). The IC50 of the most active fractions were determined to be 18.36 and $17.79 \mu \mathrm{g} / \mathrm{mL}$ for F5 and F7, respectively (Figure $2 b, c)$.

The F5 and F7 phytocannabinoid composition is described in [15]. F5 contains CBG, CBN and THC at ratios of 3.7:4.6:91.7, respectively [15]. F7 contains CBC, CBDV, CBDVA, CBG, CBN, THC, THCA at ratios of 23.5:1.8:0.9:1.3:1.9:68.9:1.7, respectively [15]. The terpene composition of F5 is reported in [15]; the terpene composition of F7 is reported in Supplementary Table S1. 

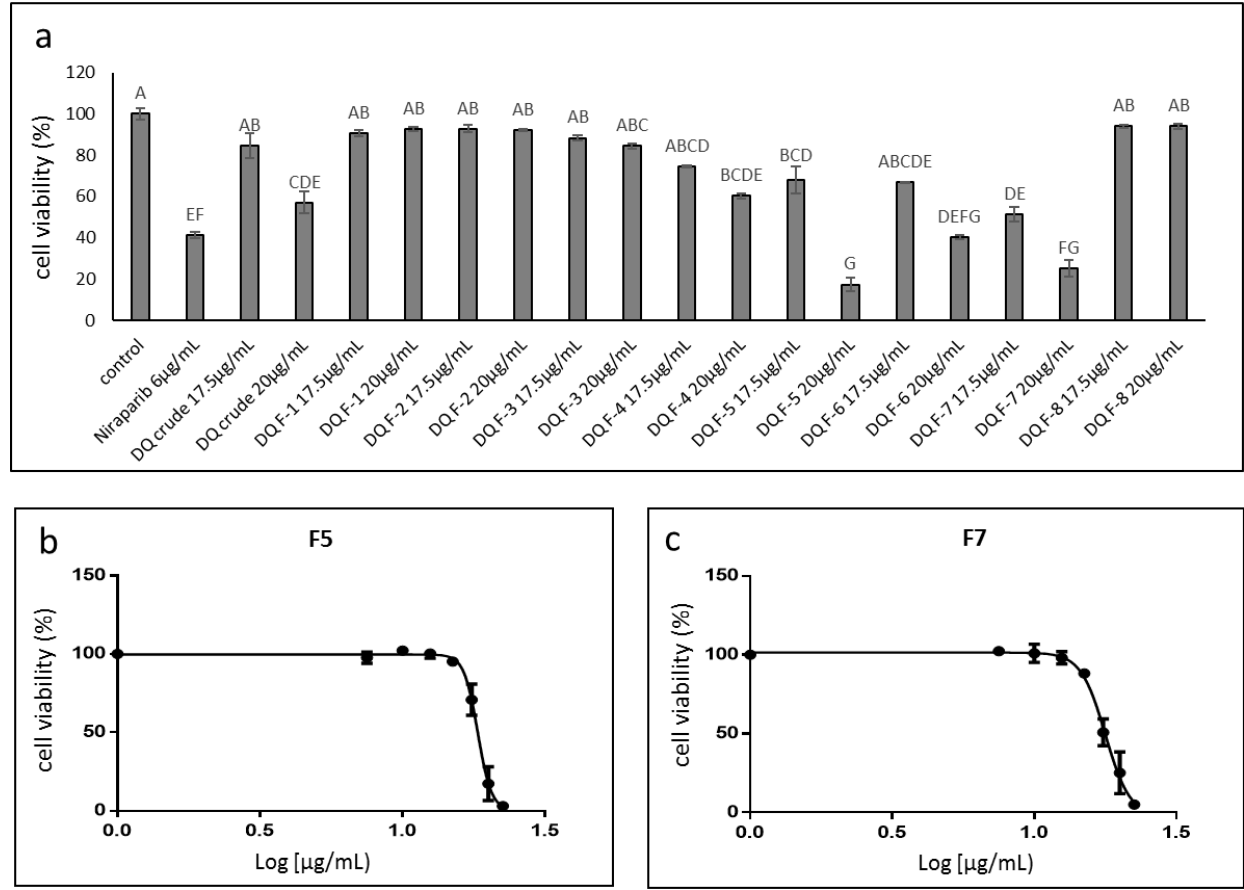

Figure 2. (a) Cell viability of HTB75 cells following treatment with DQ extract fractions F1-F8, and crude extract. Cell viability was determined by XTT assay as a function of live cell number. Control is the vehicle-treated control ( $1 \% \mathrm{v} / \mathrm{v}$ methanol). Error bars indicate $\pm S E(n=3)$. Levels with different letters are significantly different from all combinations of pairs according to the TukeyKramer honest significant difference test (HSD; P $\leq 0.05)$. (b,c) Cell viability of HTB75 cells following treatment with $C$. sativa DQ fractions F5 and F7 at different concentrations for IC50 values calculation from 5P logistic curve fit using GraphPad Prism version 6.1. Error bars indicate \pm SE $(n=3)$.

\subsection{Determining activity of the phytocannabinoids standard mixes of F5 and F7}

In order to confirm the active compositions of F5 and F7, standard mixes (SM) of phytocannabinoid standards were formulated as close as possible to the original fraction compositions. F5-SM had an IC50 of $14.67 \mu \mathrm{g} / \mathrm{mL}$ (Figure 3a), which was lower than that of F5 $(18.36 \mu \mathrm{g} / \mathrm{mL}$; Figure $2 \mathrm{~b})$. F7-SM showed IC50 value of $13.56 \mu \mathrm{g} / \mathrm{mL}$ (Figure $3 \mathrm{~b}$ ), again lower than that of F7 $(17.79 \mu \mathrm{g} / \mathrm{mL}$; Figure 2c). Activity of F5, F7 and their SM on cell viability of another ovarian cell line, HTB161, was examined. F5 was less active to some extent on this cell line in comparison to HTB75 (IC50 of 26.19 and $18.36 \mu \mathrm{g} / \mathrm{mL}$ for HTB161 and HTB75, respectively; Figure 2 and Supplementary Figure S1a). F7 was more active on this cell line in comparison to HTB75 (IC50 of 15.67 and $17.79 \mu \mathrm{g} / \mathrm{mL}$ for HTB161 and HTB75, respectively; Figure 2 and Supplementary Figure S1a). F5-SM was more active and F7-SM less active than the plant fractions on this cell line (IC50 of 25.11 and 25.09 $\mu \mathrm{g} / \mathrm{mL}$ for F5-SM and F7-SM respectively; Supplementary Figure S1b). 

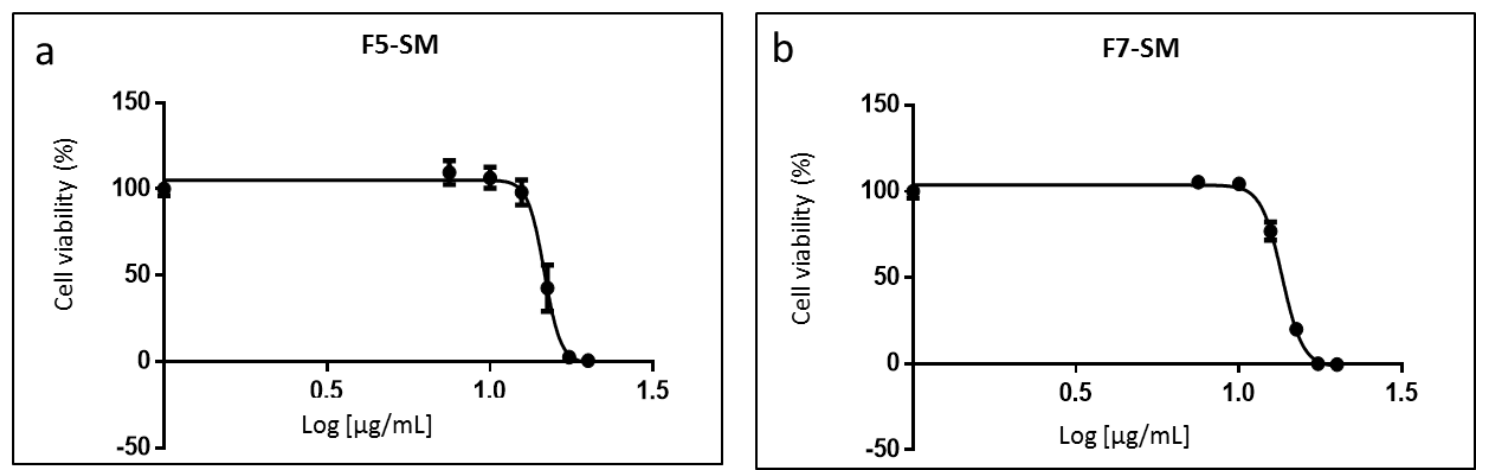

Figure 3. Cell viability of HTB75 cells following treatment with F5-SM (a) and F7-SM at different concentrations for IC50 values calculation from 5P logistic curve fit using GraphPad Prism version 6.1. Error bars indicate $\pm S E(n=3)$.

\subsection{Determining the most effective combination of phytocannabinoids}

To determine the most effective combinations of the main phytocannabinoids [8] in F5 and F7, combinations of THC, CBG, CBC and CBN standards were examined at ratios found in F5 or F7, at fixed total concentration in comparison to THC (Figure 4). At concentrations of 13 and $15 \mu \mathrm{g} / \mathrm{mL}$ (Figure $4 \mathrm{a}$ and Figure $4 \mathrm{~b}$, respectively), THC alone was less effective than some of the various combinations of THC, CBC, CBG and CBN at ratios found in F5 or F7 (Figure 4). The most effective combinations at both 13 and $15 \mu \mathrm{g} / \mathrm{mL}$ were those of $\mathrm{THC}+\mathrm{CBC}$ and $\mathrm{THC}+\mathrm{CBC}+\mathrm{CBG}$ at ratios found in $\mathrm{F} 7$ (ratios of 7.5:2.5 and 7.4:2.5:0.1, respectively; Figure 4). For the F5 combination-ratio, THC+CBG was the most effective treatment, but was not significantly different from the other F5-based combinations (Figure 4).
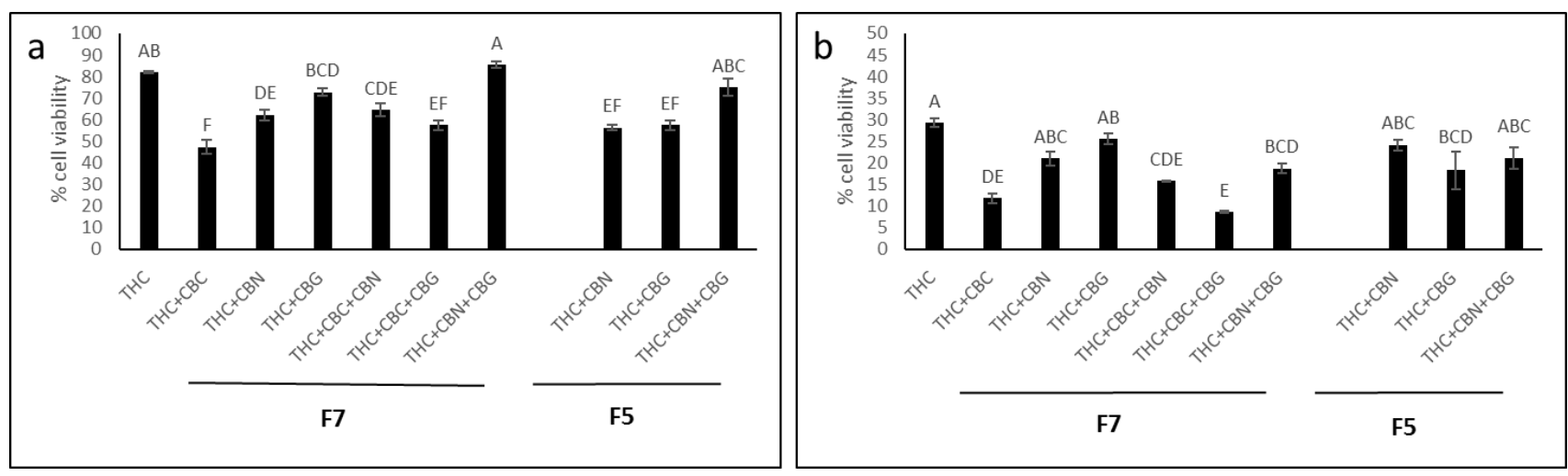

Figure 4. Cell viability of HTB75 cells following treatment with THC or with combinations of THC, CBG, CBC and CBN as in F7 or F5, at total concentrations of (a) 13 and (b) $15 \mu \mathrm{g} / \mathrm{mL}$ (treatments are listed in Supplementary Table S2). Cell viability was determined by XTT assay as a function of live cell number. All calculations are in relation to control (the vehicle treated control of $1.5 \% \mathrm{v} / \mathrm{v}$ methanol) that is considered $100 \%$ cell viability (not shown). Error bars indicate $\pm \mathrm{SE}$ $(n=3)$. Levels with different letters are significantly different from all combinations of pairs by Tukey-Kramer honest significant difference (HSD; $\mathrm{P} \leq 0.05)$.

\subsection{Determining the effect of F5, F7, F5-SM or F7-SM treatments on cell apoptosis}

Treatment with F5 and F7 for $48 \mathrm{~h}$ led to $83.3 \%$ and $88.0 \%$ cell apoptosis, respectively, in comparison to $17.3 \%$ apoptosis in the vehicle control. Treatment with the phytocannabinoid standard mixes, F5-SM and F7-SM, led to similar high levels of cell apoptosis: 93.9\% and 85.0\%, respectively (Figure 5a; Supplementary Figure S2a). The chemotherapy drug niraparib led to $64.1 \%$ apoptotic cells (Figure 5a; Supplementary Figure S2a). Only 
low levels of necrosis were recorded with the cannabis treatments, similar to the control (Figure 5a; Supplementary Figure S2a).
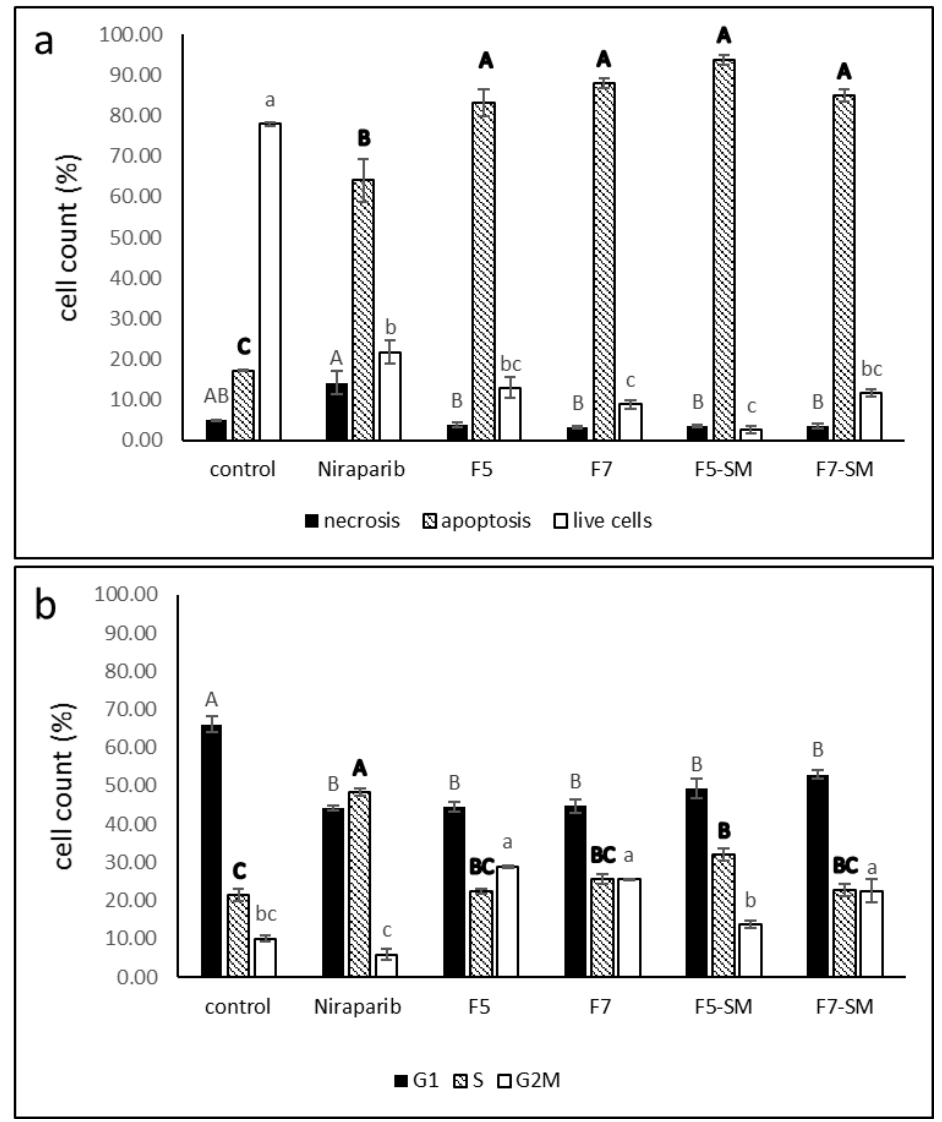

Figure 5. (a) Percentage of viable, apoptotic, or necrotic HTB75 cells following treatment with niraparib $(5.1 \mu \mathrm{g} / \mathrm{mL})$, F5 $(19.1 \mu \mathrm{g} / \mathrm{mL})$, F7 $(19.4 \mu \mathrm{g} / \mathrm{mL})$, F5-SM $(17.4 \mu \mathrm{g} / \mathrm{mL})$, or F7-SM $(16.3 \mu \mathrm{g} / \mathrm{mL})$ for $48 \mathrm{~h}$. (b) Percentage of HTB75 cells in G1, S or G2/M phase following the same treatments, except $4 \mu \mathrm{g} / \mathrm{mL}$ niraparib for $24 \mathrm{~h} .10^{4}$ cells were analyzed per treatment. Control is vehicle control $(1.5 \% \mathrm{v} / \mathrm{v}$ methanol). The treated cells were harvested and analyzed in FACS following annexin VFITC and PI staining. Error bars indicate \pm SE $(n=3)$. Levels with different letters of similar font and style are significantly different from all combinations of pairs according to the Tukey-Kramer honest significant difference (HSD; $\mathrm{P} \leq 0.05$ ).

\subsection{Determining the effect of F5, F5-SM, F7 or F7-SM treatments on cell cycle arrest}

HTB-75 treatment with F5, F7 and F7-SM for $24 \mathrm{~h}$ led to a significant increase in the percentage of cells in the G2/M phase of the cell cycle (28.9, 25.5 and $22.4 \%$, respectively) in comparison to the control (vehicle) treatment (10.1\%; Figure 5b; Supplementary Figure S2b). A slight but significant increase in S phase was recorded for the F5-SM treatment $(31.9 \%$ ) in comparison to $21.4 \%$ in the control (Figure 5b; Supplementary Figure S2b). Niraparib led mainly to S phase arrest (48.3\%) (Figure 5b; Supplementary Figure S2b).

3.7 Determination of the involvement of CB1 and CB2 receptor inverse agonists, TRPA1 receptor blocker, and TRPV1 or TRPV2 receptor antagonists on cytotoxic activity

We determined the effect of adding CB1 or CB2 inverse agonists (IA), TRPV1 or TRPV2 antagonists (AN) or a TRPA1 blocker (B) on F5, F7, F5-SM and F7-SM activity. HTB75 cells were treated with F5, F7, F5-SM or F7-SM with or without IA, AN or B. In the presence of CB2 IA, the cytotoxic effect of F5, F7, F5-SM or F7-SM was significantly reduced $(45.8,62.7,77.3,57.1 \%$, viable cells respectively, vs. 38.5, 19.3, 29.6, 26.3\% viable cells without CB2 IA); Figure 6a-d). Also, TRPV2 AN co-treatment with F7 and F7-SM interfered to some extent with their activity (significantly with F7; Figure 6b,d). Cell viability percentage for treatments with F7 or F7-SM were 48.9 or $39.2 \%$ with TRPV2 AN vs 29.6 or 
$26.3 \%$ without, respectively (Figure 6b,d). Treatments with F5, F5-SM, F7 or F7-SM in the presence of TRPV1 AN, TRPA1 B or CB1 IA, did not significantly reduced the cytotoxicity of the treatments (Figure 6a-d). Treatment with TRPV1 AN even increase to some extent the cytotoxicity of F5-SM (Figure 6c). CB1 or CB2 IA, TRPV1 or TRPV2 AN or TRPA1 B did not affect HTB75 cell viability (Figure 6e).

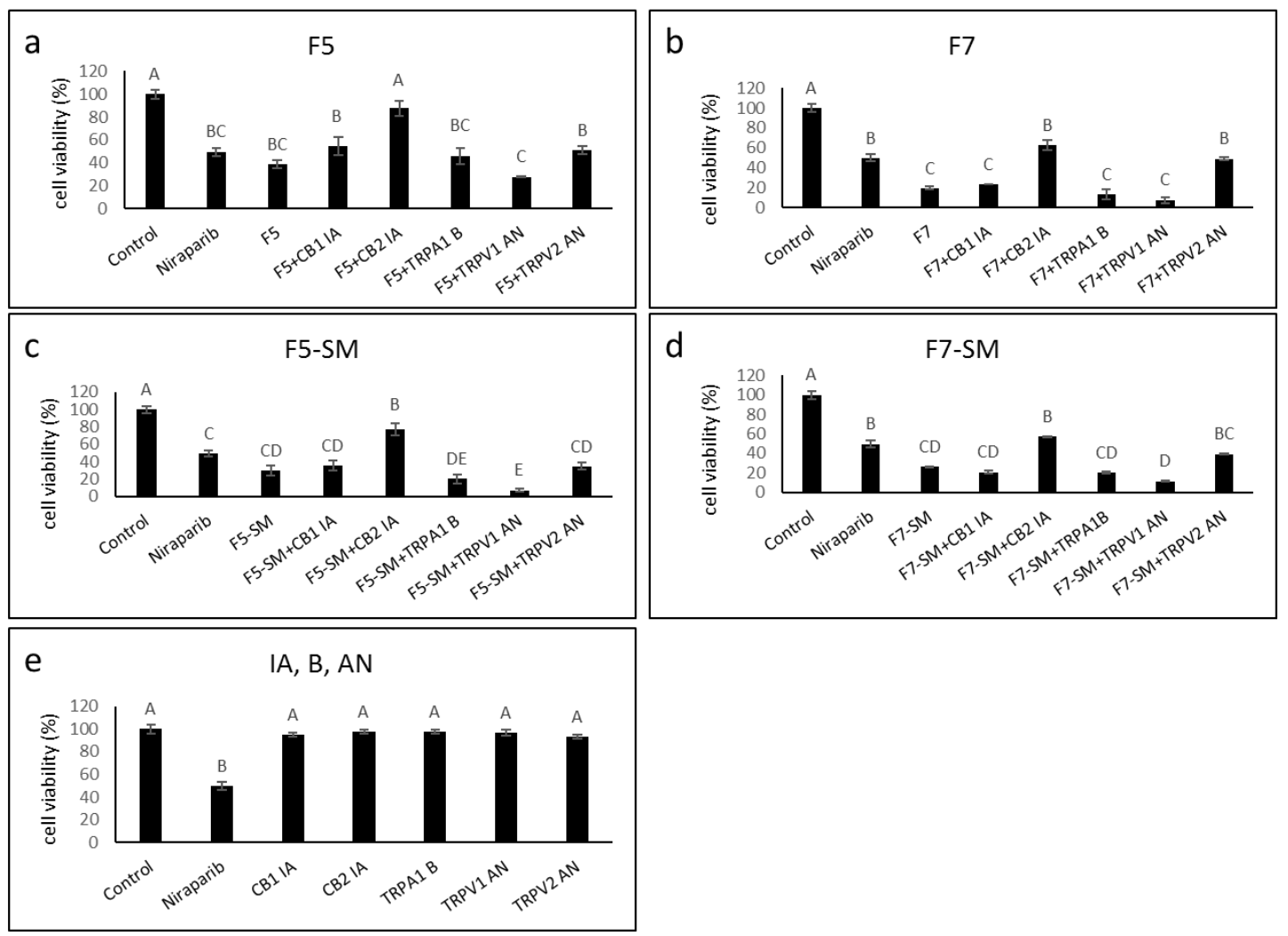

Figure 6. Cell viability of HTB75 cells following treatment with F5 (a), F7 (b), F5-SM (c) or F7-SM (d), with or without CB1 and CB2 inverse agonists (IA), a TRPA1 blocker (B), and TRPV1 or TRPV2 antagonists (AN) for $48 \mathrm{~h}$. Cells were treated with F5 $(19.1 \mu \mathrm{g} / \mathrm{mL})$, F7 $(19.4 \mu \mathrm{g} / \mathrm{mL}), \mathrm{F} 5-\mathrm{SM}$ $(14.7 \mu \mathrm{g} / \mathrm{mL})$ or F7-SM $(13.6 \mu \mathrm{g} / \mathrm{mL})$, with or without the receptor IA, B or AN $(10 \mu \mathrm{M})$. (e) The effect of IA, B or NA on cell viability. Cell viability was determined by XTT assay as a function of live cell number. Niraparib $(6 \mu \mathrm{g} / \mathrm{mL})$ served as a positive control. Control is vehicle control $(1.5 \%$ $\mathrm{v} / \mathrm{v}$ methanol $+1 \% \mathrm{DMSO})$. Error bars indicate $\pm \mathrm{SE}(\mathrm{n}=3)$. Levels with different letters are significantly different from all combinations of pairs according to the Tukey-Kramer honest significant difference (HSD; $\mathrm{P} \leq 0.05)$.

\subsection{Determining the effects of combining the most active cannabis fractions and chemotherapy drugs}

Chemotherapy drugs were examined for combined activity with F5, F7, F5-SM and F7-SM. Considerable and significant synergy (on a scale of 0 [no synergy] to 1 [high synergy]) was obtained for combinations of niraparib with F5 (with peaks of 0.6-0.8 and significant synergy at 15 or $17.5 \mu \mathrm{g} / \mathrm{mL}$ F5 and 6-8 $\mu \mathrm{g} / \mathrm{mL}$ niraparib; Figure 7a; Supplementary Table S3). Considerable and significant synergy was obtained also with combinations of niraparib and F7 (with peaks of 0.4-0.6, respectively, and significant synergy of 15 or $17.5 \mu \mathrm{g} / \mathrm{mL}$ F7 and 3-8 $\mu \mathrm{g} / \mathrm{mL}$ niraparib; Figure 7a; Supplementary Table S3). Synergy with F5-SM or F7-SM on the other hand was restricted to 0.2-0.4 only (Figure 7a; Supplementary Table S3).

Gemcitabine showed only low level of synergy with the plant fractions (peaks of 00.2 ), and in some cases inhibited activity (e.g., for $12.5 \mu \mathrm{g} / \mathrm{mL}$ F5 or F7 and 5-100 ng/mL gemcitabine; Figure 7b; Supplementary Table S4). Synergy was evident only with treatment of gemcitabine and F5-SM (a single peak of $0.2-0.4$ at $10 \mu \mathrm{g} / \mathrm{mL}$ of F5 and $2.5 \mathrm{ng} / \mathrm{mL}$ of gemcitabine; Figure 7b; Supplementary Table S4). 


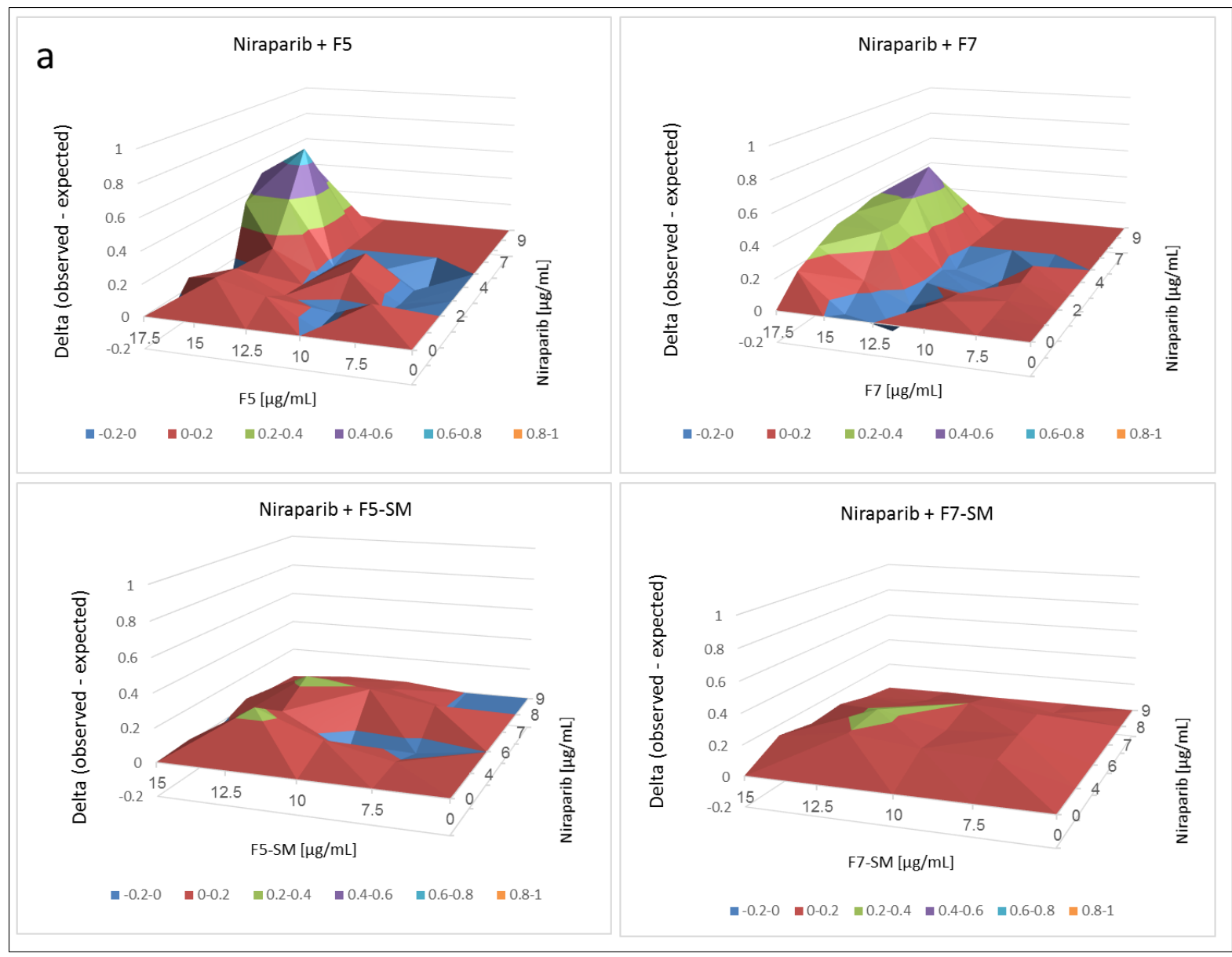




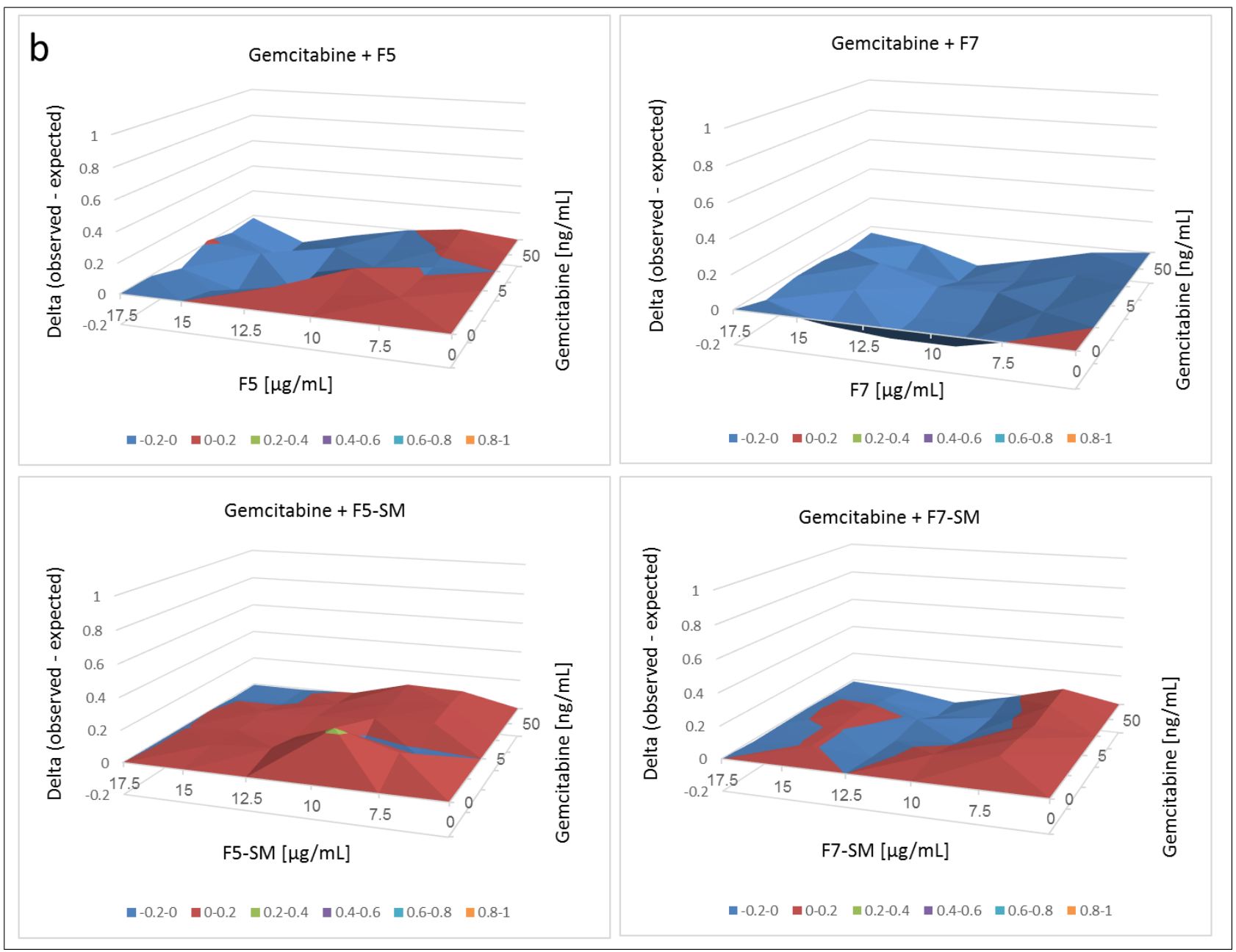

Figure 7. Synergistic interactions between F5, F7, F5-SM or F7-SM with (a) niraparib and (b) gemcitabine on cell viability of HTB75 cells following combined treatments. Synergy of cytotoxic activity calculated based on the Bliss independence drug interaction model. Synergy is apparent when the experimental (observed) value of cell survival inhibition is higher than the calculated (expected) value. Values of delta of observed minus expected values, calculated based on Bliss model are shown in the Y axis. In Supplementary Table S3 and Supplementary Table S4 are the different letters that signify different levels of the experimental (observed) values from all combinations of pairs according to the Tukey-Kramer honest significant difference test ( $n=3 ;$ HSD; $P \leq 0.05)$, for the synergistic delta values of F5, F7, F5-SM or F7-SM with niraparib or gemcitabine, respectively.

\subsection{Determining the synergistic activity on normal cells}

The cytotoxic activity of the synergistic mixture of niraparib+F5 and niraparib+F7 was assessed on normal cells using the keratinocyte (HaCaT) cell line. The synergistic ratio of mixture of niraparib:fraction $(\sim 0.53: 1.00$, derived from $8 \mu \mathrm{g} / \mathrm{mL}$ niraparib $+15 \mu \mathrm{g} / \mathrm{mL}$ F5 or F7; Figure 7a) was examined at several different concentrations; activity was examined in parallel on $\mathrm{HaCaT}$ and HTB75 cells at complete confluence (Figure 8). Some minor cell proliferation was apparent in HaCaT but not in HTB75 cells under treatments with low concentrations (Figure 8). At the cytotoxic concentrations of the mixture of synergistic-ratio of niraparib+F5 or niraparib+F7 (i.e., $8.7 \mu \mathrm{g} / \mathrm{mL}$ niraparib $+16.3 \mu \mathrm{g} / \mathrm{mL}$ F5 or F7 and $10.4 \mu \mathrm{g} / \mathrm{mL}$ niraparib $+19.6 \mu \mathrm{g} / \mathrm{mL}$ F5 or F7) considerably higher cytotoxicity was apparent against the cancer cells than against normal cells. In the most effective combined treatments of niraparib+F5 or niraparib+F7 $(10.4 \mu \mathrm{g} / \mathrm{mL}$ niraparib $+19.6 \mu \mathrm{g} / \mathrm{mL}$ F5 or F7) this activity was $\sim 50$ fold higher on HTB75 than on HaCaT cells (Figure 8). 

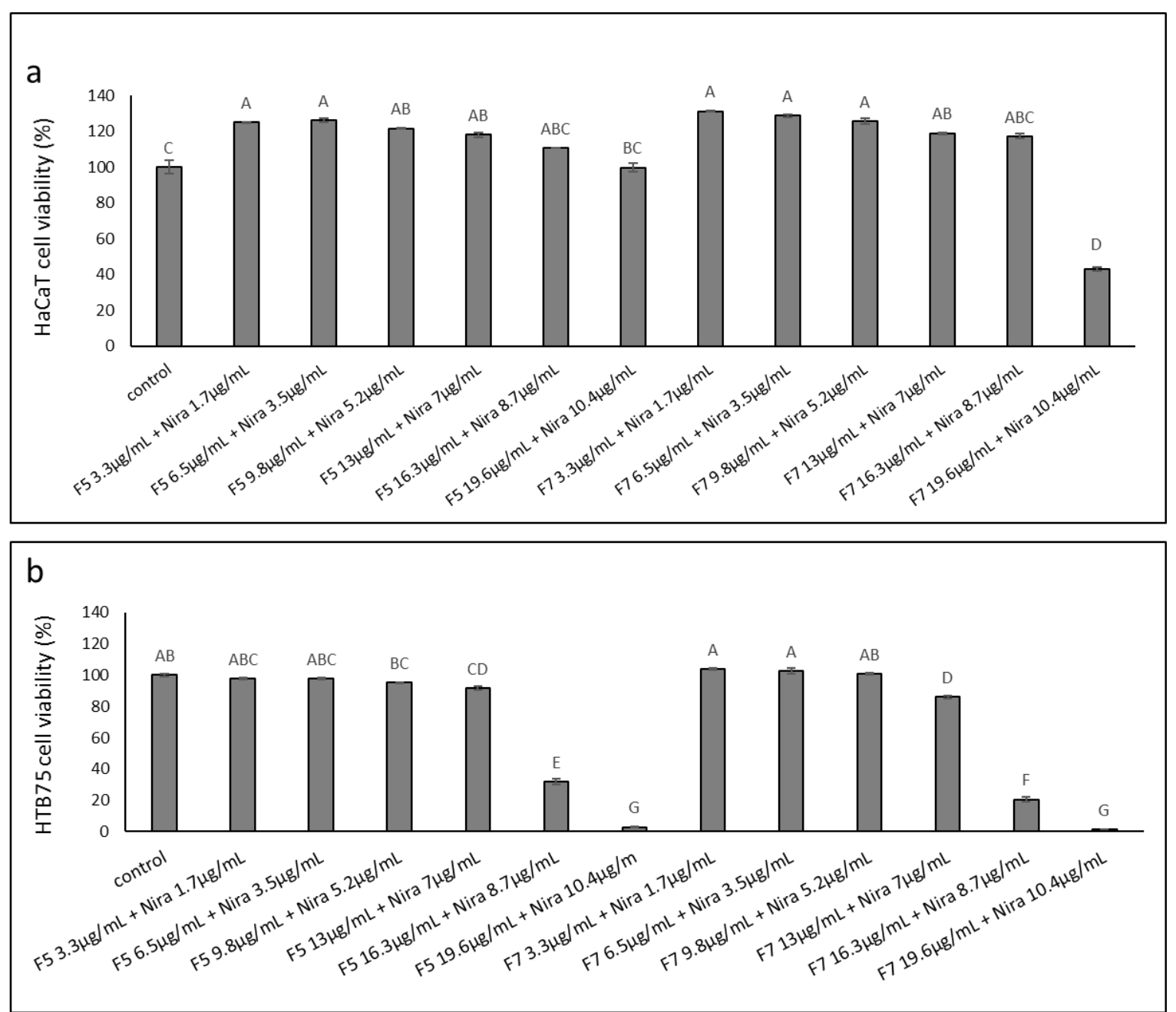

Figure 8. Cell viability of (a) HaCaT and (b) HTB75 cells following treatment at full confluence with niraparib (Nira):F5 or niraparib:F7 at ratio of 3.5:6.5, respectively, at different concentrations. Cell viability was determined by XTT assay as a function of live cell number. Control is vehicle control $(1.5 \% \mathrm{v} / \mathrm{v}$ methanol). Error bars indicate $\pm \mathrm{SE}(\mathrm{n}=3)$. Levels with different letters are significantly different from all combinations of pairs by Tukey-Kramer honest significant difference (HSD; $\mathrm{P} \leq 0.05)$.

\subsection{Determining the synergistic activity on OC patient's cells}

The cytotoxic activity of the synergistic mixture of niraparib+F5 and niraparib+F7 was assessed on OC patient's cells (MK), isolated from a cancerous deep femoral lymph node. These cells showed only low sensitivity to niraparib and no sensitivity to a combination of niraparib and F5 (Figure 9). However, a combined treatment of niraparib+F7 led to substantial cell death (Figure 9). 


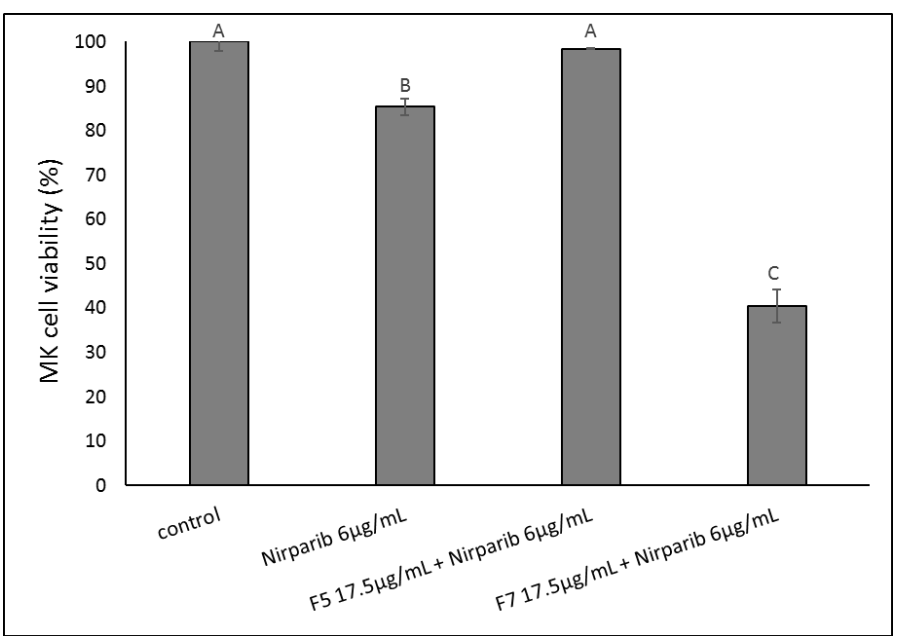

Figure 9. Cell viability of MK cells following treatment with niraparib, niraparib+F5 or niraparib+F7. Cell viability was determined by XTT assay as a function of live cell number. Control is vehicle control $(1.5 \% \mathrm{v} / \mathrm{v}$ methanol). Error bars indicate $\pm \mathrm{SE}(\mathrm{n}=2)$. Levels with different letters are significantly different from all combinations of pairs by Tukey-Kramer honest significant difference (HSD; $\mathrm{P} \leq 0.05)$.

\subsection{Determining the effect of synergistic and individual treatments of cannabis fractions and} chemotherapy drugs on cell migration

The effect of the synergistic mixture of F5, F7, niraparib+F5 and niraparib+F7 on cell migration was examined at sub-lethal concentrations using a scratch-wound assay. Almost full closure of the scratch was obtained after $48 \mathrm{~h}$ in the vehicle control $(10.1 \%$ of clear area; Figure 10). Niraparib inhibited wound closure, most apparent at $48 \mathrm{~h}(42.7 \%$ clear area; Figure 10). F5 treatment (30.4\%) and F7 treatment (29.4\%) inhibited scratch closure less than that of niraparib (Figure 10). However, the combinatory treatments of niraparib + F5 or niraparib + F7 substantially inhibited cell migration, mainly at 48 h (50.9 and $54.7 \%$ clear area, respectively; Figure 10 ). 

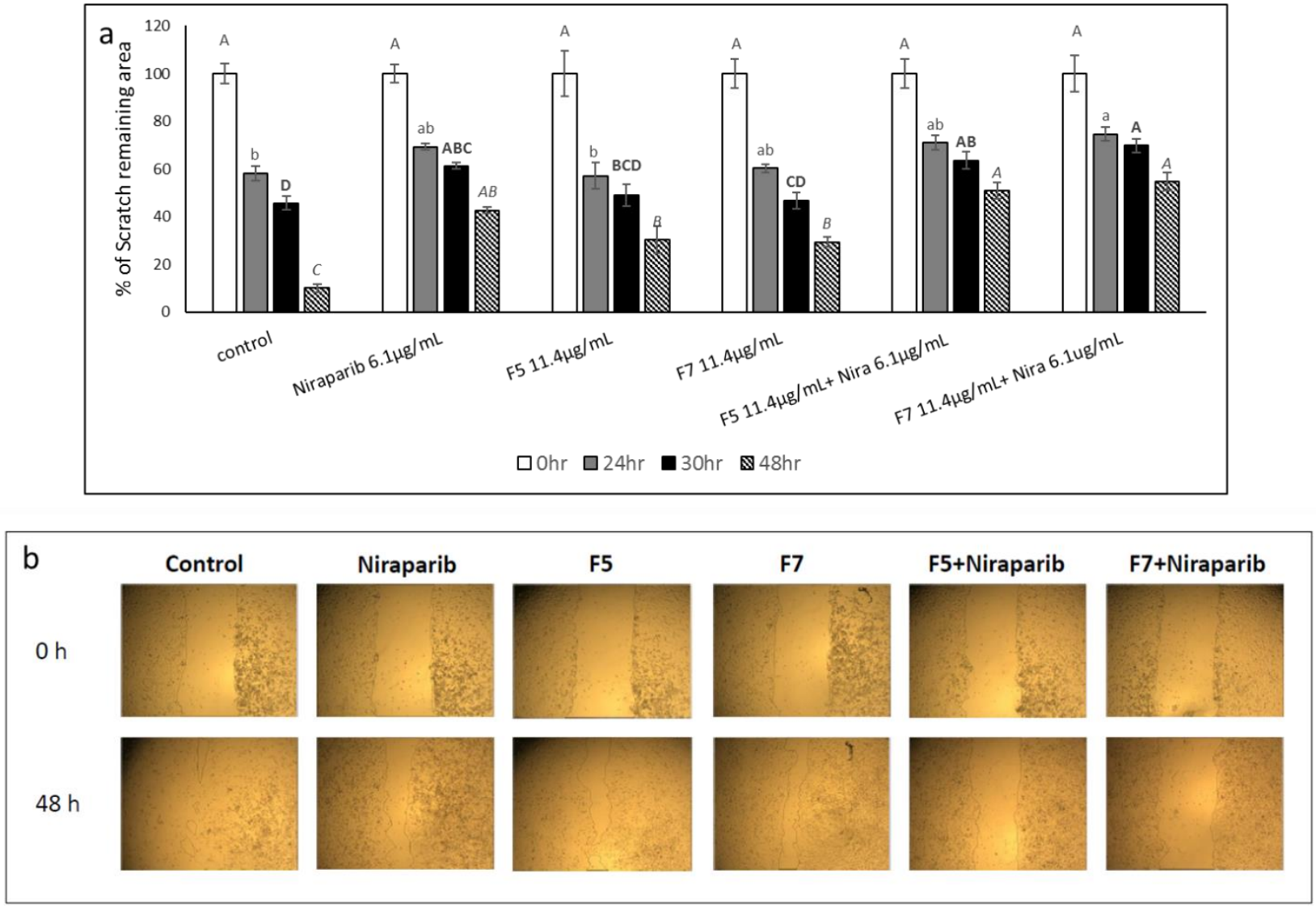

Figure 10. Effect of niraparib (Nira), F5, F7, niraparib+F5 or niraparib+F7 on HTB75 cell migration in scratch-wound assay. Control is vehicle control (1.5\% v/v methanol). (a) Percent clear scratch area is presented as mean; error bars indicate $\pm S E(n=3)$. Levels with different letters of the same font are significantly different from all combinations of pairs according to the Tukey-Kramer honest significant difference (HSD; $\mathrm{P} \leq 0.05$ ). (b) Representative images of the scratch-wound assay.

\subsection{Determining MAPK4 expression in the various synergistic and individual treatments of} cannabis fractions and chemotherapy drugs

MAPK4 gene expression was significantly reduced upon niraparib or F7 treatments in comparison to control (Figure 11). F5 treatment did not reduce this gene expression (Figure 11). In the synergistic treatments of niraparib+F5 or niraparib+F7 expression was reduced further, significantly in comparison to the individual treatments (Figure 11). 


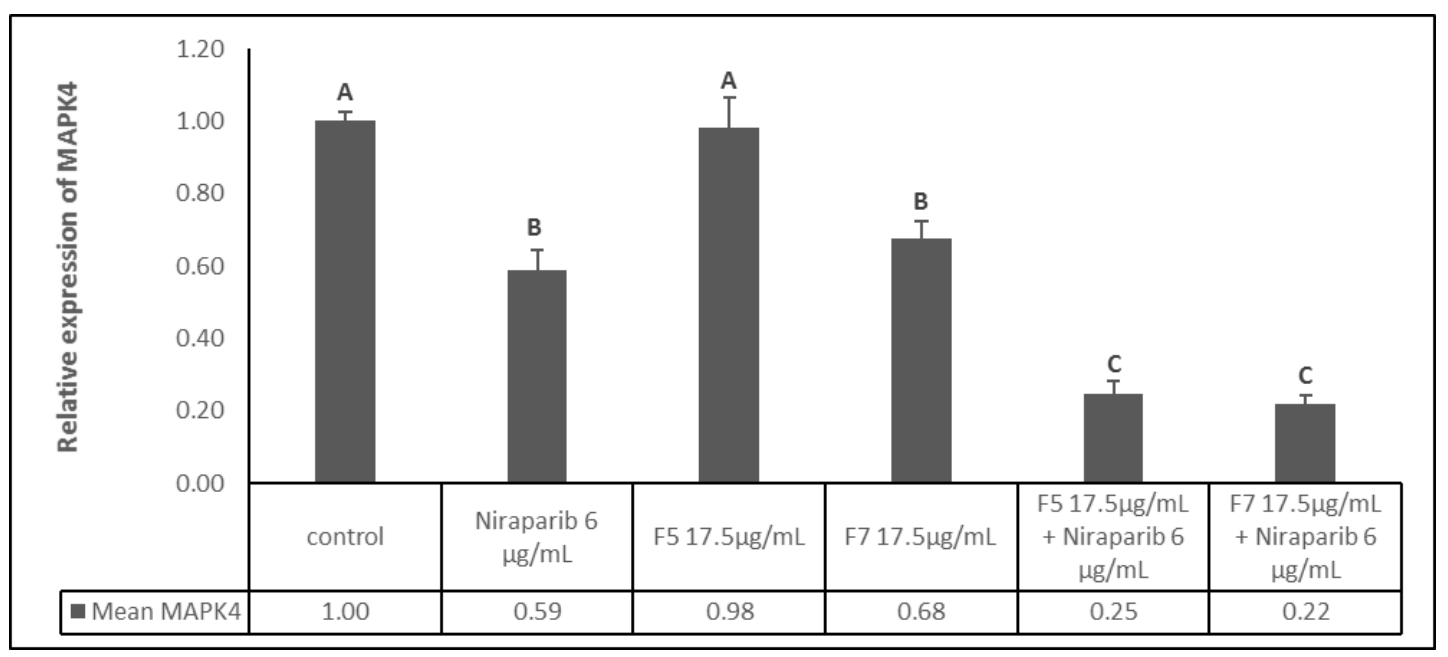

Figure 11. Quantitative PCR-based determination of the RNA steady state level in HTB75 cell line of MAPK4 after treatment with niraparib, F5, F7 or combination of niraparib+F5 or niraparib+F7, for $6 \mathrm{~h}$ relative to control. Gene transcript values were determined by quantitative PCR as a ratio between the target gene versus a reference gene (HPRT). Values were calculated relative to the average expression of target genes in treated versus control using the $2^{\Delta \Delta \mathrm{Ct}}$ method. Control $(1.5 \%$ $\mathrm{v} / \mathrm{v}$ methanol) treatment served as solvent (vehicle) control; Error bars indicate \pm S.E. $(n=3)$. Levels with different letters are significantly different from all combinations of pairs by Tukey-Kramer honest significant difference (HSD; $\mathrm{P} \leq 0.05$ ).

\section{Discussion}

We have identified two compositions of phytocannabinoid mixtures from the extract of a high-THC cannabis strain with significant cytotoxic activity against OC cell lines, HTB75 and HTB161, both high-grade serous ovarian cancer [19]. To identify the active compounds, the crude extract was fractionated and active fractions were identified. Unlike in other studies $[15,16]$, the active fractions exhibited only a minor advantage for cytotoxic activity over the crude extract.

The fractions contained both phytocannabinoids and terpenes. However, once phytocannabinoid standards alone were used, in the ratio found in each of the fractions (i.e., F5-SM, F7-SM), cytotoxic activity increased substantially. These results suggest that the active compounds for the cytotoxic activity against OC cell lines are the phytocannabinoids, and the terpenes or other unidentified compounds present in both the crude extract and fractions may interfere with this activity.

The most active fraction, F7, contains THC and $\mathrm{CBC}$ at approximately a 3:1 ratio, and CBG, CBDV and CBN in small amounts. F5 contains $91 \%$ of THC, and small amounts of CBG, THCV and CBN. Following, the most effective combinations of the main phytocannabinoids $[6,8]$ for cytotoxic activity against OC cells were determined. Combinations of THC and CBC as in F7 were the most effective, with or without CBG. In F5 combinations, that of THC+CBG was highly active. These combinations were more effective than THC only.

Another fraction that contained THC, i.e., DQ-F6 [15], had cytotoxic activity against OC but to a lesser extent than F5 or F7. F6 contained more THC in relation to CBG in comparison to F7, and contained no CBC [15], which may explain its lower activity.

In multiple studies, THC and CBG have been suggested to possess anticancer activity for a variety of cancer types, in vitro, in vivo and for THC also in clinical trials [20]. CBC was shown to have anticancer activity on prostate carcinomas [21]. In addition, we previously found that a combination of THC and CBC was highly active against urothelial carcinoma cells [22]. Together, this study and others (e.g., [15,16,22]), highlight the im- 
portance of the appropriate combination of compounds for high specific anti-cancer activity in vitro; in the case of cytotoxicity to OC cells, a combination of THC and CBC with or without CBG.

Treatment with F5, F7, F5-SM or F7-SM led to an increase in apoptotic cell death in HTB75 cells. In multiple previous studies, phytocannabinoids were shown to induce apoptosis in cancer cells and to inhibit cancer cell proliferation [9,11]. Cell cycle arrest resulted in apoptosis in many cases [23]. In our study, cannabis treatments led to a significant increase in G2/M or S arrest, suggesting cell cycle arrest.

CB2 IA significantly blocked the cytotoxic activity of F5, F7 and their corresponding standard mixes. CB2 was overexpressed in malignant endometrial carcinoma cells but not in healthy cells [24].

The TRPV2 antagonist reduced the cytotoxic activity of F7 and F7-SM to some extent, suggesting that TRPV2 might be involved in the activity of these compounds on HTB75 cells. A study that examined protein expression in cancer tissues and adjacent normal tissues of OC patients revealed that TRPV2 is expressed in OC tissues at higher levels than in adjacent normal tissues. A significant increase in TRPV2 expressions in OC was also correlated with severity of tumor growth according to clinical stage [25]. Taken together, the higher level of TRPV2 and CB2 expression in malignant tissues may position TRPV2 and CB2 as target-receptors for cannabis-based therapy.

Neither the TRPA1 blocker, the TRPV1 antagonist nor the CB1 inverse agonist reduced activity, suggesting TRPA1, TRPV1 and CB1 are not involved in the cytotoxic activity of these compounds on HTB75 cells.

A plausible approach for treatment of OC patient is to combine the cannabis-based treatment with chemotherapy. Hence, we examined the effect of co-treatment of cannabis and chemotherapy drugs on HTB75 cell viability. Niraparib is a potent Poly (ADP-ribose) polymerase (PARP)-1 and PARP-2 inhibitor. PARPs are a family of nuclear proteins that allocate single-strand breaks in DNA, bind and activate recruitment of repair factors. These processes are important for cell proliferation. PARP inhibition by niraparib leads to cell cycle arrest and cell apoptosis [26, 27]. Niraparib treatment led in our study to $S$ phase arrest; indeed, PARP inhibition was previously shown to converts single strand breaks to double strand breaks during DNA replication in the S phase of the cell cycle [26], yet other studies niraparib was shown to induce cell cycle arrest mainly in the G2/M phase [27].

We found that niraparib acts synergistically with F5 and F7 at some of the examined concentrations, and is less synergistic with the standard mixes F5-SM or F7-SM. The fact that the plant fractions, containing both phytocannabinoids and terpenes, acted synergistically with the chemotherapy drugs, while the phytocannabinoids alone exhibited less, suggests that terpenes or other compounds present in the fractions facilitate this synergy. Gemcitabine did not show substantial synergistic activity with the cannabis-based treatments.

Moreover, the mixture of niraparib+F5 or niraparib+F7 at the synergistic ratio was $\sim 50$ fold more cytotoxic to HTB75 cells than to normal keratinocytes (HaCaT cells), once examined under complete confluence (to reduce non-cancerous cell proliferation in control treatment). The low cytotoxicity to normal cells may suggests that treatment with F5 or F7 in combination with niraparib could prove to be an effective and cancer-specific treatment. Supporting this suggestion, the combination of F7+niraparib showed activity on an OC patient's cells isolated from a cancerous deep femoral lymph node.

Niraparib or F7 treatments led to substantial reduction in MAPK4 expression. Members of the MAPK family are key regulator of cell proliferation, growth, and survival processes, and have implications in the response to cancer therapy [28]. MAPK4 is suggested to regulate DNA damage repair [29] and to promote tumor progression via noncanonical activation of AKT/mTOR signaling [30]. Specific to OC, MAPK4 upregulation was found to enhance cell proliferation and migration of cancer cells [31]. Importantly, it was shown that silencing MAPK4 expression in triple-negative breast cancer cells could enhance the sensitivity of these cells to PARP1 inhibitors and reduce the possibility of PARP1 inhibitor resistance [29]. Combined treatment including MAPK4 silencing and the PARP1 inhibitor 
olaparib inhibited cell proliferation and promoted apoptosis in these cells [29]. Also, in cervical cancer cells, MAPK4 knockdown and PARP1 inhibition exerted synergistic effects by activating AKT phosphorylation [32]. This suggests that the observed synergy between niraparib and the phytocannabinoids occurs because suppression of MAPK4 expression that enhances the PARP inhibitor cytotoxic activity on OC cells.

Reduction or abolishment of MAPK4 expression is associated with reduction in cell migration [29, 31]. Overexpression of PARP1 promoted the wound-healing process in non-small cell lung cancer [33] and a combined treatment of the PARP1 inhibitor olaparib and silencing of MAPK4 expression further reduced cell migration in triple-negative breast cancer cells [29]. In agreement, we show here that treatment of OC cells with F7 that significantly inhibit MAPK4 expression, reduced cell migration, and that the co-treatment of F5 or F7 with niraparib reduced cell migration even more.

However, the fact that only niraparib+F7 treatment and not niraparibe+F5 was effective on MK cells suggests that the reduction of MAPK4 expression by itself is not sufficient to convey cell death of OC cells isolated from a cancerous deep femoral lymph node. Additionally, F5 treatment did not lead to reduction of MAPK4 expression but inhibited cell migration. Differences in mechanism of activity between F5 and F7 should be further examined.

To conclude, we identified cannabis compounds with substantial cytotoxic activity against OC cells in vitro, which involves cell cycle arrest and apoptosis. This activity was found to be considerably stronger on cancer cells than on normal cells. Indeed, CB2 and TRPV2, which might be involved with the compound's activity, are expressed more often in malignant tissue. Hence, cannabis-based therapies targeting cancer cells with reduced effect on the healthy surrounding tissues may be envisioned. Moreover, we identified synergistic activity between the cannabis extract fractions and niraparib. Since F5 and F7 treatments substantially reduced MAPK4 expression, this synergistic activity might be based on the known synergy between the repression of MAPK4 expression and the inhibition of PARP1 activity. Our results indicate that cannabis might be regarded as a complementary and effective anti-cancer treatment for OC. Given the favorable safety profile of phytocannabinoids compared to standard pharmacotherapy (e.g., [34]), we propose that clinical trials with cannabis-based products are needed desperately for OC patients.

Supplementary Materials: The following are available online at www.mdpi.com/xxx/s1, Figure S1: Cell viability of HTB161 cells following treatment with C. sativa DQ fraction F5 (a), F7 (b), F5-SM (c) and F7-SM (d) at different concentrations. The IC50 values were calculated from 5P logistic curve fit using GraphPad Prism version 6.1. Error bars indicate \pm SE ( $n=3$ ). Figure S2: (a) Annexin V-FITC and PI staining for determining the proportion of viable (Q4), apoptotic (Q2 and Q3 for late and early apoptosis, respectively) or necrotic HTB75 cells (Q1). (b) Example of FACS output following PI staining for determining the stages of HTB75 cell cycle arrest. Treatments included niraparib (5.1 $\mu \mathrm{g} / \mathrm{mL})$, F5 (19.1 $\mu \mathrm{g} / \mathrm{mL})$, F7 $(19.4 \mu \mathrm{g} / \mathrm{mL})$, F5-SM $(17.4 \mu \mathrm{g} / \mathrm{mL})$ or F7-SM $(16.3 \mu \mathrm{g} / \mathrm{mL})$ on the HTB75 cell line for $24 \mathrm{~h}$ for cell cycle and $48 \mathrm{~h}$ for apoptosis. Methanol (control) treatment served as a solvent (vehicle) control. Table S1: The F7 terpene composition. Table S2: Treatment layout with THC, CBG, CBC and CBN standards on HTB75 cell line. Table S3: Different letters signify delta values that are significantly different from all combinations of pairs according to Tukey-Kramer honest significant difference (HSD; $\mathrm{P} \leq 0.05$ ). Delta values calculated according to the Bliss model between the experimental (observed) and the calculated (expected) values of the synergistic interactions between F5, F7, F5-SM or F7-SM and niraparib on cell viability of HTB75 cells following combined treatments. Delta values are graphically presented in Figure 7a. Table S4: Different letters signify delta values that are significantly different from all combinations of pairs according to Tukey-Kramer honest significant difference (HSD; $\mathrm{P} \leq 0.05)$. Delta values calculated according to Bliss model between the experimental (observed) and the calculated (expected) values of the synergistic interactions between F5, F7, F5-SM or F7-SM and gemcitabine on cell viability of HTB75 cells following combined treatments. Delta values are graphically presented in Figure $7 \mathrm{~b}$.

Author Contributions: HK, NS and MK contributed to study conception and design. Material preparation, data collection and analysis were performed by ACV, SMA and NS. The first draft of the manuscript was written by HK, NS and MK, and all authors commented on subsequent versions of 
the manuscript. The final draft was completed by HK, and all authors read and approved the final manuscript.

Funding: Research was funded by Canna Onc Research. NS, ACJ, SMA and HK are employees or research associates of the Agriculture Research Organization, funded by the State of Israel.

Data Availability Statement: Data supporting reported results can be found in Supplementary data.

Acknowledgments: We thank Dr. Einav Mayzlish Gati and Ofer Cohen for providing the IGB strains and Zach Dunseth for English editing.

Conflicts of Interest: MK owns Canna Onc Research, so she has a conflict of interest. However, NS, ACJ, SMA and HK are not employees of the company and have no financial or personal relationships with Canna Onc Research, and therefore have no conflict of interest. There was no compromise in the investigators' judgement in conducting or reporting this research results.

\section{Supplementary data}
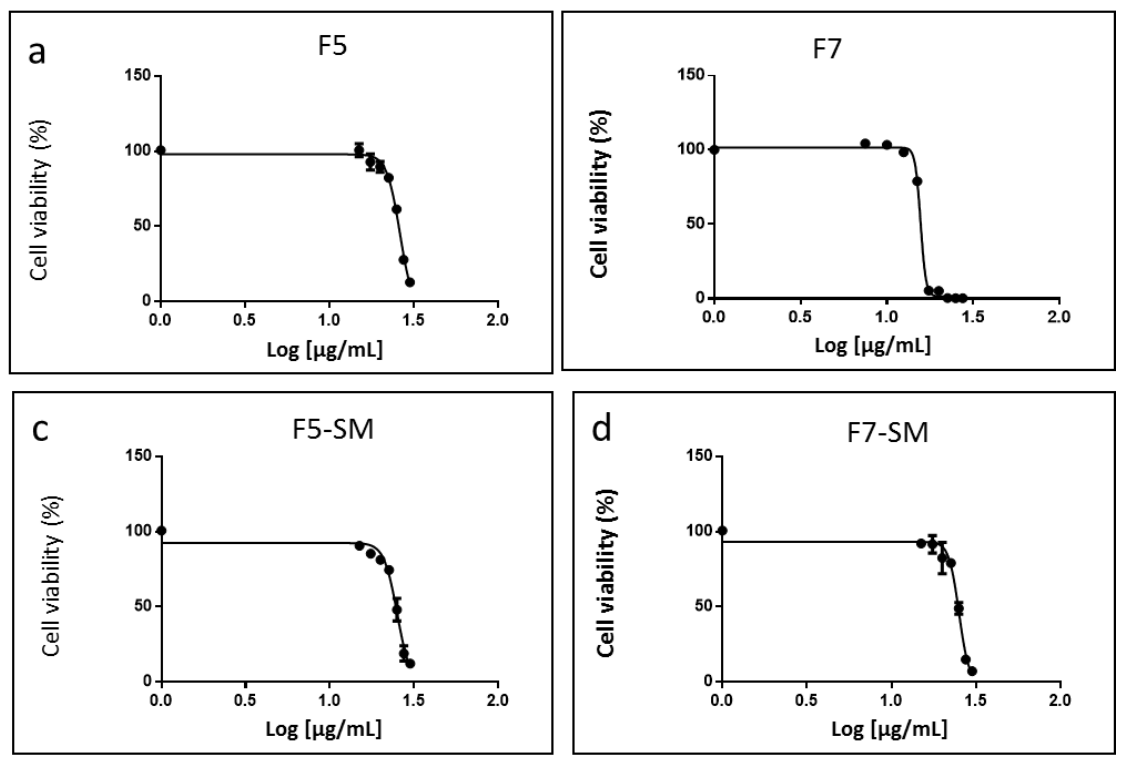

Supplementary Figure S1. Cell viability of HTB161 cells following treatment with C. sativa DQ fraction F5 (a), F7 (b), F5-SM (c) and F7-SM (d) at different concentrations. The IC50 values were calculated from 5P logistic curve fit using GraphPad Prism version 6.1. Error bars indicate \pm SE $(n=3)$. 

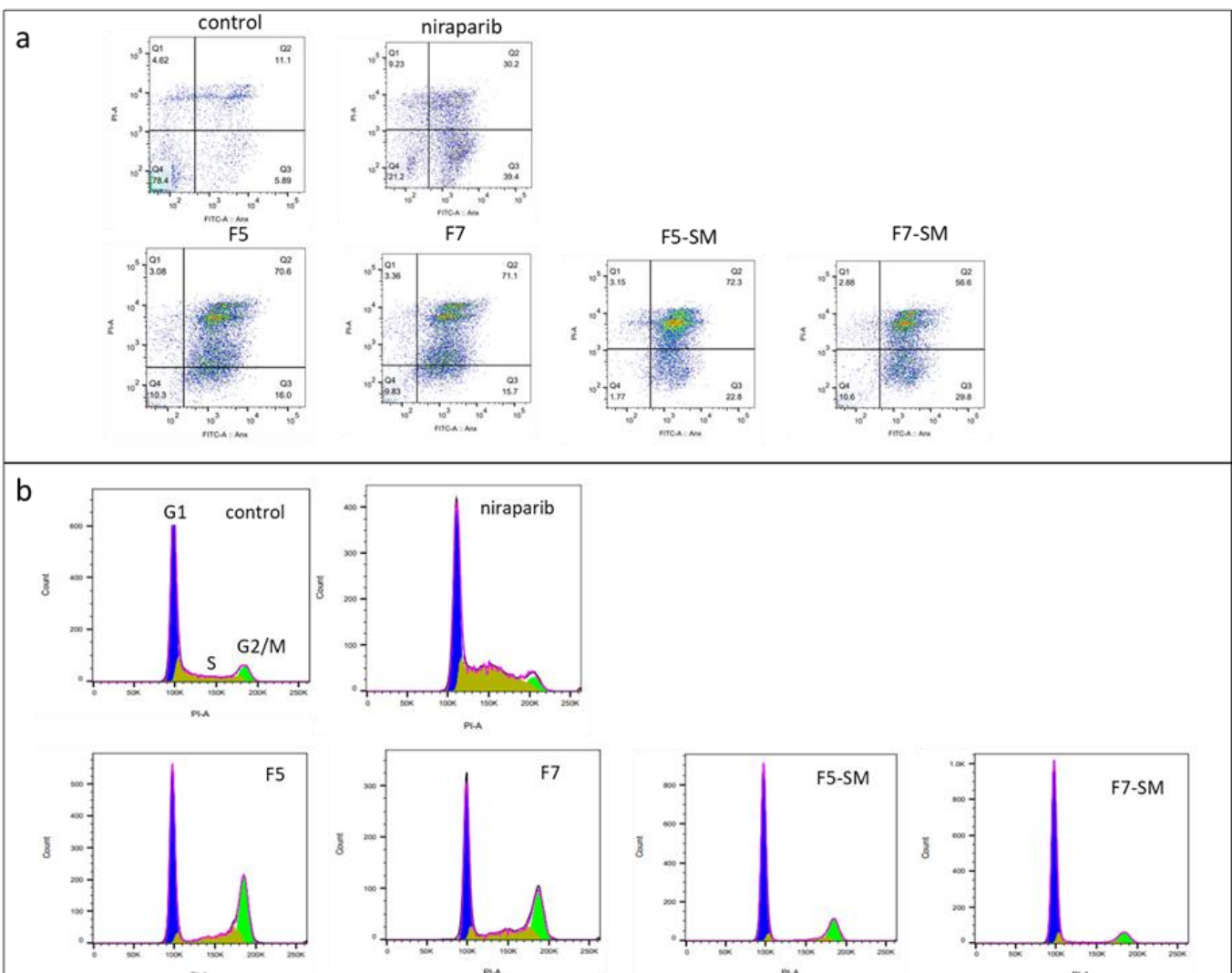

Supplementary Figure S2. (a) Annexin V-FITC and PI staining for determining the proportion of viable (Q4), apoptotic (Q2 and Q3 for late and early apoptosis, respectively) or necrotic cells (Q1). (b) Example of FACS output following PI staining for determining the stages of cell cycle arrest. Treatments included niraparib $(5.1 \mu \mathrm{g} / \mathrm{mL})$, F5 $(19.1 \mu \mathrm{g} / \mathrm{mL})$, F7 $(19.4 \mu \mathrm{g} / \mathrm{mL})$, F5-SM $(17.4 \mu \mathrm{g} / \mathrm{mL})$ or F7-SM $(16.3 \mu \mathrm{g} / \mathrm{mL})$ on the HTB75 cell line for $24 \mathrm{~h}$ for cell cycle and $48 \mathrm{~h}$ for apoptosis. Methanol (control) treatment served as a solvent (vehicle) control. 
Supplementary Table S1. The F7 composition of terpenes.

\begin{tabular}{|c|c|}
\hline Compound & $\%$ of total compounds in F7 \\
\hline D-Limonene & 0.37 \\
\hline$\alpha$ Bergamotene & 3.62 \\
\hline Caryophyllene & 62.64 \\
\hline (-)-Guaia-6,9-diene & 0.59 \\
\hline$\gamma$ Gurjunene & 0.46 \\
\hline$\gamma$ Muurolene & 1.90 \\
\hline onaphthalene & 2.24 \\
\hline$\alpha$ selinene & 1.86 \\
\hline$\beta$ selinene & 5.29 \\
\hline Bicyclogermacrene & 2.26 \\
\hline Cadina-1(10),4-diene & 0.51 \\
\hline$\alpha$ Guaiene & 1.15 \\
\hline$\beta$ Guaiene & 6.08 \\
\hline Alloaromadendrene & 1.28 \\
\hline Selina-3,7(11)-diene & 7.92 \\
\hline$\beta$ maaliene & 1.85 \\
\hline
\end{tabular}

Supplementary Table S2. Treatment layout with THC, CBG, CBC and CBN standards on the HTB75 cell line.

\begin{tabular}{ccccccccccc}
\hline & & \multicolumn{3}{c}{ F7 } & & & & & \multicolumn{2}{c}{ F5 } \\
\hline THC & 13.0 & 9.8 & 12.8 & 12.8 & 9.7 & 9.7 & 12.6 & 12.4 & 12.5 & 11.9 \\
CBC & & 3.2 & & & 3.2 & 3.2 & & & \\
CBN & & & 0.2 & & 0.2 & & 0.2 & 0.6 & 0.6 \\
CBG & & & & 0.2 & & 0.1 & 0.2 & & 0.5 & 0.5 \\
\hline Total $\mu \mathrm{g} / \mathrm{mL}$ & 13.0 & 13.0 & 13.0 & 13.0 & 13.0 & 13.0 & 13.0 & 13.0 & 13.0 & 13.0 \\
\hline THC & 15.0 & 11.3 & 14.8 & 14.8 & 11.1 & 11.2 & 14.5 & 14.3 & 14.4 & 13.8 \\
CBC & & 3.7 & & & 3.7 & 3.7 & & & & \\
CBN & & & 0.2 & & 0.2 & & 0.2 & 0.7 & 0.6 \\
CBG & & & & 0.2 & & 0.2 & 0.2 & & 0.6 & 0.6 \\
\hline Total $\mu \mathrm{gg} / \mathrm{mL}$ & 15.0 & 15.0 & 15.0 & 15.0 & 15.0 & 15.0 & 15.0 & 15.0 & 15.0 & 15.0 \\
\hline
\end{tabular}


Supplementary Table S3. Different letters signify delta values that are significantly different from all combinations of pairs according to Tukey-Kramer honest significant difference (HSD; $\mathrm{P} \leq 0.05$ ). Delta values calculated according to the Bliss model between the experimental (observed) and the calculated (expected) values of the synergistic interactions between F5, F7, F5-SM or F7-SM and niraparib on cell viability of HTB75 cells following combined treatments. Delta values are graphically presented in Figure 7a.

\begin{tabular}{|c|c|c|c|c|c|c|c|}
\hline & \multicolumn{7}{|c|}{ F5 $[\mu \mathrm{g} / \mathrm{mL}]$} \\
\hline \multirow{11}{*}{ 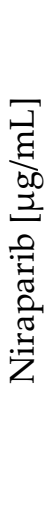 } & & 0 & 7.5 & 10 & 12.5 & 15 & 17.5 \\
\hline & 0 & FGH & FGH & FGH & FGH & FGH & FGH \\
\hline & 1 & FGH & DEFG & FGH & FG & CDEF & $\mathrm{GH}$ \\
\hline & 2 & FGH & FGH & FGH & FGH & DEF & FG \\
\hline & 3 & FGH & FGH & EFG & FGH & FGH & FGH \\
\hline & 4 & FGH & FGH & DEF & FGH & DEFG & $\mathrm{H}$ \\
\hline & 6 & FGH & $\mathrm{H}$ & FGH & FGH & BC & $\mathrm{BCD}$ \\
\hline & 7 & FGH & N/A & $\mathrm{N} / \mathrm{A}$ & $\mathrm{N} / \mathrm{A}$ & A & $\mathrm{AB}$ \\
\hline & 8 & FGH & N/A & N/A & N/A & $\mathrm{AB}$ & BCDE \\
\hline & 9 & FGH & $\mathrm{N} / \mathrm{A}$ & $\mathrm{N} / \mathrm{A}$ & N/A & FG & FG \\
\hline & 10 & FGH & $\mathrm{N} / \mathrm{A}$ & $\mathrm{N} / \mathrm{A}$ & $\mathrm{N} / \mathrm{A}$ & FGH & FGH \\
\hline \multicolumn{8}{|c|}{ F7 $[\mu \mathrm{g} / \mathrm{mL}]$} \\
\hline \multirow{11}{*}{ 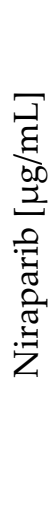 } & & 0 & 7.5 & 10 & 12.5 & 15 & 17.5 \\
\hline & 0 & GHIJ & GHIJ & GHIJ & GHIJ & GHIJ & GHIJ \\
\hline & 1 & GHIJ & GHIJ & EFGH & IJ & HIJ & CDEFC \\
\hline & 2 & GHIJ & GHI & GHI & HIJ & FGHI & BCDEF \\
\hline & 3 & GHIJ & FGH & HIJ & GHIJ & $\mathrm{BC}$ & BC \\
\hline & 4 & GHIJ & EFGH & HIJ & GHIJ & $\mathrm{BCD}$ & $\mathrm{BC}$ \\
\hline & 6 & GHIJ & HIJ & $\mathrm{J}$ & HIJ & $\mathrm{AB}$ & B \\
\hline & 7 & GHIJ & N/A & N/A & N/A & $\mathrm{A}$ & $\mathrm{AB}$ \\
\hline & 8 & GHIJ & N/A & N/A & N/A & $\mathrm{AB}$ & BCDE \\
\hline & 9 & GHIJ & N/A & N/A & N/A & DEFGH & EFGH \\
\hline & 10 & GHIJ & N/A & N/A & N/A & GHI & GHI \\
\hline \multirow{8}{*}{ 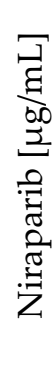 } & \multicolumn{7}{|c|}{ F5-SM $[\mu \mathrm{g} / \mathrm{mL}]$} \\
\hline & & 0 & 7.5 & 10 & 12.5 & 15 & \\
\hline & 0 & $\mathrm{HI}$ & HI & HI & $\mathrm{HI}$ & $\mathrm{HI}$ & \\
\hline & 4 & $\mathrm{HI}$ & EFGHI & CDEF & A & GHI & \\
\hline & 6 & $\mathrm{HI}$ & IJ & $\mathrm{J}$ & $\mathrm{BCD}$ & HIJ & \\
\hline & 7 & HI & $\mathrm{BC}$ & $\mathrm{AB}$ & A & CDEFGH & \\
\hline & 8 & $\mathrm{HI}$ & $\mathrm{HI}$ & CDEFG & $\mathrm{CDE}$ & FGHI & \\
\hline & 9 & $\mathrm{HI}$ & $\mathrm{HI}$ & DEFGH & DEFGH & HI & \\
\hline \multirow{8}{*}{ 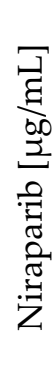 } & \multicolumn{7}{|c|}{ F7-SM $[\mu \mathrm{g} / \mathrm{mL}]$} \\
\hline & & 0 & 7.5 & 10 & 12.5 & 15 & \\
\hline & 0 & G & G & G & G & G & \\
\hline & 4 & G & $\mathrm{ABCDEF}$ & $\mathrm{ABC}$ & $\mathrm{AB}$ & ABCDE & \\
\hline & 6 & G & $\mathrm{ABC}$ & $\mathrm{ABCD}$ & A & BCDEFG & \\
\hline & 7 & G & $\mathrm{ABC}$ & $\mathrm{AB}$ & $\mathrm{ABC}$ & BCDEFG & \\
\hline & 8 & G & CDEFG & $\mathrm{ABCDE}$ & CDEFG & CDEFG & \\
\hline & 9 & G & FG & $\mathrm{H}$ & DEFG & EFG & \\
\hline
\end{tabular}


Supplementary Table S4. Different letters signify delta values that are significantly different from all combinations of pairs according to Tukey-Kramer honest significant difference (HSD; $\mathrm{P} \leq 0.05$ ). Delta values calculated according to Bliss model between the experimental (observed) and the calculated (expected) values of the synergistic interactions between F5, F7, F5-SM or F7-SM and gemcitabine on cell viability of HTB75 cells following combined treatments. Delta values are graphically presented in Figure $7 \mathrm{~b}$.

\begin{tabular}{|c|c|c|c|c|c|c|}
\hline \multicolumn{7}{|c|}{ F5 $[\mu \mathrm{g} / \mathrm{mL}]$} \\
\hline & 0 & 7.5 & 10 & 12.5 & 15 & 17.5 \\
\hline 0 & $\mathrm{ABCDE}$ & $\mathrm{ABCDE}$ & $\mathrm{ABCDE}$ & $\mathrm{ABCDE}$ & $\mathrm{ABCDE}$ & $\mathrm{ABCDE}$ \\
\hline 2.5 & $\mathrm{ABCDE}$ & $\mathrm{AB}$ & $\mathrm{ABCD}$ & $\mathrm{ABCD}$ & EFGH & ABCDEF \\
\hline 5 & $\mathrm{ABCDE}$ & $\mathrm{ABCD}$ & A & $\mathrm{J}$ & $\mathrm{J}$ & GHI \\
\hline 10 & $\mathrm{ABCDE}$ & BCDEFG & DEFGH & $\mathrm{IJ}$ & CDEFGH & $\mathrm{ABC}$ \\
\hline 50 & $\mathrm{ABCDE}$ & $\mathrm{ABC}$ & CDEFGH & FGHI & $\mathrm{J}$ & CDEFGH \\
\hline 100 & $\mathrm{ABCDE}$ & $\mathrm{AB}$ & ABCDEF & $\mathrm{HI}$ & $\mathrm{J}$ & BCDEFGH \\
\hline \multicolumn{7}{|c|}{$\mathrm{F} 7[\mu \mathrm{g} / \mathrm{mL}]$} \\
\hline & 0 & 7.5 & 10 & 12.5 & 15 & 17.5 \\
\hline 0 & A & $\mathrm{A}$ & $\mathrm{A}$ & A & A & A \\
\hline 2.5 & A & DEF & IJ & K & FGH & $\mathrm{ABCD}$ \\
\hline 5 & A & $\mathrm{BCD}$ & $\mathrm{HI}$ & JK & $\mathrm{ABCD}$ & $\mathrm{ABC}$ \\
\hline 10 & A & $\mathrm{CDE}$ & DEF & DEFG & $\mathrm{AB}$ & $\mathrm{ABC}$ \\
\hline 50 & A & $\mathrm{BCD}$ & EFGH & IJK & GHI & $\mathrm{ABCD}$ \\
\hline 100 & $\mathrm{~A}$ & $\mathrm{ABC}$ & DEFG & $\mathrm{HI}$ & $\mathrm{CDE}$ & $\mathrm{ABC}$ \\
\hline \multicolumn{7}{|c|}{ F5-SM [ $\mu \mathrm{g} / \mathrm{mL}]$} \\
\hline & 0 & 7.5 & 10 & 12.5 & 15 & 17.5 \\
\hline 0 & $\mathrm{BC}$ & $\mathrm{BC}$ & $\mathrm{BC}$ & $\mathrm{BC}$ & BC & $\mathrm{BC}$ \\
\hline 2.5 & $\mathrm{BC}$ & $\mathrm{AB}$ & $\mathrm{A}$ & $\mathrm{BC}$ & $\mathrm{BC}$ & $\mathrm{BC}$ \\
\hline 5 & $\mathrm{BC}$ & $\mathrm{BC}$ & C & $\mathrm{BC}$ & $\mathrm{BC}$ & $\mathrm{BC}$ \\
\hline 10 & $\mathrm{BC}$ & $\mathrm{ABC}$ & $\mathrm{ABC}$ & $\mathrm{BC}$ & $\mathrm{BC}$ & $\mathrm{BC}$ \\
\hline 50 & $\mathrm{BC}$ & $\mathrm{AB}$ & $\mathrm{ABC}$ & $\mathrm{BC}$ & $\mathrm{BC}$ & $\mathrm{BC}$ \\
\hline 100 & $\mathrm{BC}$ & $\mathrm{AB}$ & $\mathrm{AB}$ & $\mathrm{BC}$ & $\mathrm{BC}$ & $\mathrm{BC}$ \\
\hline \multicolumn{7}{|c|}{ F7-SM $[\mu \mathrm{g} / \mathrm{mL}]$} \\
\hline & 0 & 7.5 & 10 & 12.5 & 15 & 17.5 \\
\hline 0 & CDEFGH & CDEFGH & CDEFGH & CDEFGH & CDEFGH & CDEFGH \\
\hline 2.5 & CDEFGH & A & $\mathrm{ABCD}$ & EFGHI & BCDEFG & DEFGHI \\
\hline 5 & CDEFGH & $\mathrm{AB}$ & DEFGHI & FGHIJ & BCDEFG & DEFGHI \\
\hline 10 & CDEFGH & $\mathrm{ABCDE}$ & HIJK & DEFGHI & $\mathrm{ABCDEF}$ & DEFGHI \\
\hline 50 & CDEFGH & $\mathrm{ABC}$ & IJK & JK & DEFGHI & DEFGHI \\
\hline 100 & CDEFGH & $\mathrm{A}$ & EFGHI & $\mathrm{K}$ & GHIJ & DEFGHI \\
\hline
\end{tabular}

\section{References}

1. Cortez, A. J.; Tudrej, P.; Kujawa, K. A.; Lisowska, K. M., Advances in ovarian cancer therapy. Cancer Chemother. Pharmacol. 2018, $81,17-38$.

\section{2. https://cancerstatisticscenter.cancer.org/\#!/cancer-site/Ovary}

3. Menon, U.; Gentry-Maharaj, A.; Burnell, M.; Singh, N.; Ryan, A.; Karpinskyj, C.; Carlino, G.; Taylor, J.; Massingham, S. K.; Raikou, M., Ovarian cancer population screening and mortality after long-term follow-up in the UK Collaborative Trial of Ovarian Cancer Screening (UKCTOCS): a randomised controlled trial. Lancet 2021, 397, 2182-2193.

4. Barnett, R., Ovarian cancer. Lancet 2016, 387, 1265. 
5. Corroon, J.; Sexton, M.; Bradley, R., Indications and administration practices amongst medical cannabis healthcare providers: A cross-sectional survey. BMC Fam. Pract. 2019, 20, 1-12.

6. Hanuš, L. O.; Meyer, S. M.; Muñoz, E.; Taglialatela-Scafati, O.; Appendino, G., Phytocannabinoids: a unified critical inventory. Nat. Prod. Rep. 2016, 33, 1357-1392.

7. Gülck, T.; Møller, B. L., Phytocannabinoids: origins and biosynthesis. Trends Plant Sci. 2020, 25, 985-1004.

8. Aizpurua-Olaizola, O.; Soydaner, U.; Oztürk, E.; Schibano, D.; Simsir, Y.; Navarro, P.; Etxebarria, N.; Usobiaga, A., Evolution of the cannabinoid and terpene content during the growth of Cannabis sativa plants from different chemotypes. J. Nat. Prod. 2016, 79, 324-331.

9. Ramer, R.; Hinz, B., Cannabinoids as anticancer drugs. Adv. Pharmacol. 2017, 80, 397-436.

10. Baram, L.; Peled, E.; Berman, P.; Yellin, B.; Besser, E.; Benami, M.; Louria-Hayon, I.; Lewitus, G. M.; Meiri, D., The heterogeneity and complexity of Cannabis extracts as antitumor agents. Oncotarget 2019, 10, 4091.

11. Velasco, G.; Sánchez, C.; Guzmán, M., Towards the use of cannabinoids as antitumour agents. Nat. Rev. Cancer 2012, 12, 436-444.

12. Fraguas-Sánchez, A. I.; Torres-Suárez, A. I.; Cohen, M.; Delie, F.; Bastida-Ruiz, D.; Yart, L.; Martin-Sabroso, C.; Fernández-Carballido, A., PLGA nanoparticles for the intraperitoneal administration of CBD in the treatment of ovarian cancer: In Vitro and In Ovo assessment. Pharmaceutics 2020, 12, 439.

13. Fraguas-Sánchez, A.; Fernández-Carballido, A.; Delie, F.; Cohen, M.; Martin-Sabroso, C.; Mezzanzanica, D.; Figini, M.; Satta, A.; Torres-Suárez, A., Enhancing ovarian cancer conventional chemotherapy through the combination with cannabidiol loaded microparticles. Eur. J. Pharm. Biopharm. 2020, 154, 246-258.

14. Barrie, A. M.; Gushue, A. C.; Eskander, R. N., Dramatic response to Laetrile and cannabidiol (CBD) oil in a patient with metastatic low grade serous ovarian carcinoma. Gynecol. Oncol. Rep. 2019, 29, 10.

15. Peeri, H.; Shalev, N.; Vinayaka, A. C.; Nizar, R.; Kazimirsky, G.; Namdar, D.; Anil, S. M.; Belausov, E.; Brodie, C.; Koltai, H., Specific Compositions of Cannabis sativa Compounds Have Cytotoxic Activity and Inhibit Motility and Colony Formation of Human Glioblastoma Cells In Vitro. Cancers 2021, 13, 1720.

16. Mazuz, M.; Moyal, L.; Hodak, E.; Nadarajan, S.; Vinayaka, A. C.; Gorovitz-Haris, B.; Lubin, I.; Drori, A.; Drori, G.; Van Cauwenberghe, O., Synergistic cytotoxic activity of cannabinoids from cannabis sativa against cutaneous T-cell lymphoma (CTCL) invitro and ex-vivo. Oncotarget 2020, 11, 1141.

17. Narasimhan, V.; Wright, J. A.; Churchill, M.; Wang, T.; Rosati, R.; Lannagan, T. R.; Vrbanac, L.; Richardson, A. B.; Kobayashi, H.; Price, T., Medium-throughput drug screening of patient-derived organoids from colorectal peritoneal metastases to direct personalized therapy. Clinical Cancer Research 2020, 26, 3662-3670.

18. Pauli, C.; Hopkins, B. D.; Prandi, D.; Shaw, R.; Fedrizzi, T.; Sboner, A.; Sailer, V.; Augello, M.; Puca, L.; Rosati, R., Personalized in vitro and in vivo cancer models to guide precision medicine. Cancer Discov. 2017, 7, 462-477.

19. Mitra, A. K.; Davis, D. A.; Tomar, S.; Roy, L.; Gurler, H.; Xie, J.; Lantvit, D. D.; Cardenas, H.; Fang, F.; Liu, Y., In vivo tumor growth of high-grade serous ovarian cancer cell lines. Gynecologic oncology 2015, 138, 372-377.

20. Tomko, A. M.; Whynot, E. G.; Ellis, L. D.; Dupré, D. J., Anti-cancer potential of cannabinoids, terpenes, and flavonoids present in cannabis. Cancers 2020, 12, 1985.

21. De Petrocellis, L.; Ligresti, A.; Schiano Moriello, A.; Iappelli, M.; Verde, R.; Stott, C.G.; Cristino, L.; Orlando, P.; Di Marzo, V. NonTHC cannabinoids inhibit prostate carcinoma growth in vitro and in vivo: pro-apoptotic effects and underlying mechanisms. $B r$. J. Pharmacol. 2013, 168, 79-102.

22. Anis, O.; Vinayaka, A. C.; Shalev, N.; Namdar, D.; Nadarajan, S.; Anil, S. M.; Cohen, O.; Belausov, E.; Ramon, J.; Mayzlish Gati, E., Cannabis-derived compounds cannabichromene and $\Delta 9$-tetrahydrocannabinol interact and exhibit cytotoxic activity against urothelial cell carcinoma correlated with inhibition of cell migration and cytoskeleton organization. Molecules 2021, $26,465$.

23. Houtgraaf, J. H.; Versmissen, J.; van der Giessen, W. J., A concise review of DNA damage checkpoints and repair in mammalian cells. Cardiovasc. Revasc. Med. 2006, 7, 165-172. 
24. Guida, M.; Ligresti, A.; De Filippis, D.; D'Amico, A.; Petrosino, S.; Cipriano, M.; Bifulco, G.; Simonetti, S.; Orlando, P.; Insabato, L., The levels of the endocannabinoid receptor CB2 and its ligand 2-arachidonoylglycerol are elevated in endometrial carcinoma. Endocrinology 2010, 151, 921-928.

25. Ren, X.; Hao, W.; Liu, J.; Li, Y.; Wang, B.; Zu, X.; Xue, H., Study on the clinical significance of TRPV2 and MMP2 expressions in ovarian cancer. Biocell 2021, 45, 521.

26. Bridges, K. A.; Toniatti, C.; Buser, C. A.; Liu, H.; Buchholz, T. A.; Meyn, R. E., Niraparib (MK-4827), a novel poly (ADP-Ribose) polymerase inhibitor, radiosensitizes human lung and breast cancer cells. Oncotarget 2014, 5, 5076.

27. Caruso, D.; Papa, A.; Tomao, S.; Vici, P.; Panici, P. B.; Tomao, F., Niraparib in ovarian cancer: results to date and clinical potential. Ther. Adv. Med. Oncol. 2017, 9, 579-588.

28. Braicu, C.; Buse, M.; Busuioc, C.; Drula, R.; Gulei, D.; Raduly, L.; Rusu, A.; Irimie, A.; Atanasov, A. G.; Slaby, O., A comprehensive review on MAPK: a promising therapeutic target in cancer. Cancers 2019, 11, 1618.

29. Zeng, X.; Jiang, S.; Ruan, S.; Guo, Z.; Guo, J.; Liu, M.; Ye, C.; Dong, J., MAPK4 silencing together with a PARP1 inhibitor as a combination therapy in triple-negative breast cancer cells. Mol. Med. Rep. 2021, 24, 1-8.

30. Wang, W.; Shen, T.; Dong, B.; Creighton, C. J.; Meng, Y.; Zhou, W.; Shi, Q.; Zhou, H.; Zhang, Y.; Moore, D. D., MAPK4 overexpression promotes tumor progression via noncanonical activation of AKT/mTOR signaling. J. Clin. Invest. 2019, 129, 1015-1029.

31. Du, S.; Huang, X.; Li, N.; Lv, C.; Lv, C.; Wei, M.; Gao, Z.; Zhang, Y., MiR-127-3p inhibits proliferation of ovarian cancer in rats through down-regulating MAPK4. Eur. Rev. Med. Pharmacol. Sci. 2020, 24, 10383-10390.

32. Tian, S.; Lou, L.; Tian, M.; Lu, G.; Tian, J.; Chen, X., MAPK4 deletion enhances radiation effects and triggers synergistic lethality with simultaneous PARP1 inhibition in cervical cancer. Journal of Experimental \& Clinical Cancer Research 2020, 39, (1), 1-11.

33. Chen, K.; Li, Y.; Xu, H.; Zhang, C.; Li, Z.; Wang, W.; Wang, B., An analysis of the gene interaction networks identifying the role of PARP1 in metastasis of non-small cell lung cancer. Oncotarget 2017, 8, 87263.

34. Nutt, D. J.; Phillips, L. D.; Barnes, M. P.; Brander, B.; Curran, H. V.; Fayaz, A.; Finn, D. P.; Horsted, T.; Moltke, J.; Sakal, C., A multicriteria decision analysis comparing pharmacotherapy for chronic neuropathic pain, including cannabinoids and cannabis-based medical products. Cannabis Cannabinoid Res. 2021. DOI: 10.1089/can.2020.0129 